\title{
Why Are U.S. Firms Holding So Much Cash? An Exploration of Cross-Sectional Variation
}

\author{
Łuan M. Sánchez and Emircan Yurdagül
}

\begin{abstract}
Currently U.S. firms hold record amounts of cash. The authors explore cross-sectional variation in cash holdings of U.S. publicly traded firms to shed light on the reasons for this recent trend. First, they identify factors that correlate with cash holdings and then examine the evolution of these factors over the past decade. Several factors, including research and development expenditures and idiosyncratic uncertainty, are important in accounting for cross-sectional differences in cash holdings. However, these factors do not increase over time as cash holdings do; thus, it seems unlikely that they underlie the increase in cash holdings. Aggregate uncertainty, however, has recently reached record levels. This uncertainty, combined with the fact that (idiosyncratic) uncertainty correlates well with cash holdings in the cross section of firms, suggests aggregate uncertainty may be an important factor accounting for the recent trend in increased cash holdings. (JEL E43, E44, E62, G33)
\end{abstract}

Federal Reserve Bank of St. Louis Review, July/August 2013, 95(4), pp. 293-325.

C urrently U.S. corporations have record-high cash holdings. Many argue that this phenomenon is related to the sluggish recovery of the economy: Firms holding more cash are investing less, and this prevents the economy from taking off. While referring to the cash holdings of Apple, the president of a business association stated "Why wasn't Apple spending that money on expansion, new products and jobs? The answer is uncertainty-uncertainty over new taxes" (Brunell, 2011). The concern about cash holdings is also present in the academic literature, where the rise in cash holdings of firms has been associated with several factors, including many that started more than a decade ago. This article evaluates the role played by potential firm-level determinants cited in the academic literature by examining the cross section of publicly traded firms. In addition, it provides some evidence suggesting cash holdings may relate to aggregate uncertainty.

In theory, transaction costs and precautionary motives are the main reasons firms hold cash. On the one hand, transaction costs associated with liquidating certain assets make cash preferable in response to movements in the market. Thus, holding cash can be important because

Juan M. Sánchez is an economist at the Federal Reserve Bank of St. Louis. Emircan Yurdagül is a technical research associate at the Federal Reserve Bank of St. Louis and a PhD student at Washington University in St. Louis.

○ 2013, The Federal Reserve Bank of St. Louis. The views expressed in this article are those of the author(s) and do not necessarily reflect the views of the Federal Reserve System, the Board of Governors, or the regional Federal Reserve Banks. Articles may be reprinted, reproduced, published, distributed, displayed, and transmitted in their entirety if copyright notice, author name(s), and full citation are included. Abstracts, synopses, and other derivative works may be made only with prior written permission of the Federal Reserve Bank of St. Louis. 


\section{Sánchez and Yurdagül}

it facilitates firms' responses to profitable opportunities. On the other hand, cash holdings are desirable as a cushion to soften adverse movements in the market, especially for firms with borrowing constraints.

If a factor is to be considered important in explaining the rise in cash holdings, it must satisfy the following two characteristics: (i) It must correlate with cash holdings in the cross section of firms and (ii) it must have increased over the period during which cash holdings increased. Thus, to evaluate each factor, we construct one variable that captures differences in that factor across firms and study the cross-sectional correlation of that variable with cash holdings and its evolution over the past several years. The goal of this analysis is to identify factors that can potentially do well in accounting for the recent increase in cash holdings. Factors that correlate with cash holdings in the cross section of firms and that increased during the past decade are actually good candidates. Of course, correlation does not imply causation, and the analysis here is just a first step in trying to understand the recent increase in cash holdings.

We use Compustat data that cover publicly traded companies. This dataset includes detailed annual balance sheet information, enabling the tracking of various activities and conditions for each firm. However, since the dataset does not cover privately held companies, the patterns identified in this article do not necessarily reflect the behavior of all U.S. firms.

The article is organized as follows. The next section shows the pattern of cash holdings through time in the U.S. economy and the cash-holding behavior in the cross sections of U.S. firms. In the following section, we examine various other indicators of firms' actions and conditions and study how these variables, defined at the individual firm level, relate to the cash holding of corporations in our sample. We then look for explanations in the aggregate trends of productivity volatility and policy uncertainty and follow with our conclusion. ${ }^{1}$

\section{CASH HOLDINGS OF U.S. FIRMS}

In this section, we describe various facts regarding the cash-holding behavior of U.S. firms. Our main focus is on the increasing weight of cash and equivalently liquid assets on firms' balance sheets. We first describe the time pattern of cash holdings. We then study the cross section of firms and describe the distribution in the overall sample and within various subgroups.

\section{Recent Trends in Cash Holdings}

A persistent and increasing pattern in cash holdings since the 1980s is notable in the aggregate behavior of U.S. firms (Figure 1, left panel). However, the pattern is much steeper after the mid-1990s. Specifically, the annual growth rate from 1979 to 1995 was around 6.5 percent, while after that point until 2011 the growth rate was above 9 percent. Stated differently, by 2011 U.S. firms were holding 4 times as much cash as they were holding in 1995 and 11 times as much as they were holding in 1979.

In the rest of the paper, we exclude financial companies and utility companies, as is standard in the literature. We do so because these groups of firms hold cash for different reasons, including regulations. After this exclusion, the scale of the aggregate cash holdings changes significantly, 


\section{Figure 1}

\section{Aggregate Cash by U.S. Firms}
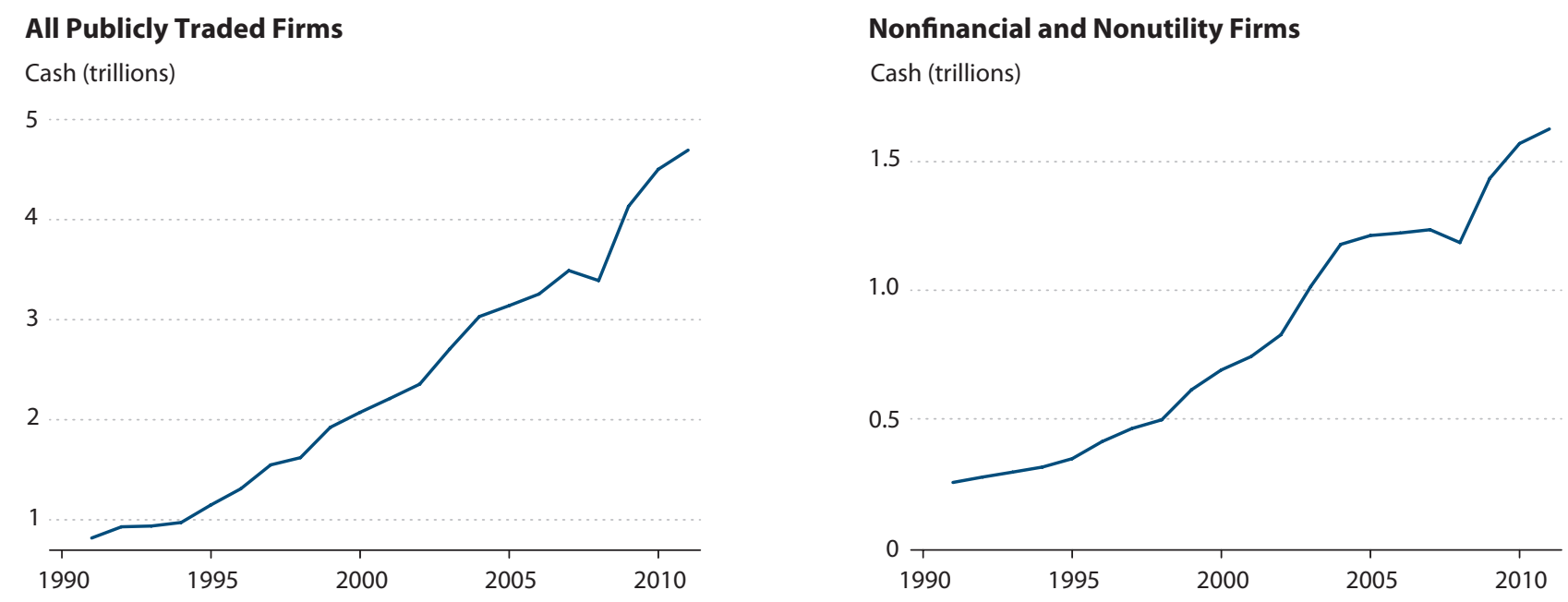

SOURCE: Compustat.

but the trend mentioned earlier changes only slightly (see Figure 1, right panel). In particular, from 1979 to 1995 the annual growth rate of cash holdings was close to 7 percent, while from 1995 to 2011 it was as high as 10 percent.

Although the trend in the aggregate levels of cash holdings is striking, in part this may simply be due to economic growth or inflation. The fraction of assets in the form of cash is a better measure that can be used to make healthier conclusions. Henceforth, we focus on the cash ratio, which is defined as the ratio of cash and equivalents to total assets:

$$
\text { CashRatio }_{i t}=\frac{\text { Cash }_{i t}}{\text { Assets }_{i t}},
$$

where subindex $i$ denotes the individual firm and $t$ the period.

Figure 2 shows the trend of this normalized variable of cash holdings. Even though it is not as monotone as for the aggregates, the cash ratio increased substantially over the past three decades. The median of the cash ratio across firms increased at an annual rate of 4 percent from 1990 to 2000. After 2000, the trend is even steeper, until 2005. In particular, the annual growth rate from 2000 to 2005 exceeded 11 percent. This high point was followed by a drop until 2008 in an interval with the crisis, after which the cash ratio recovered very quickly. Overall, the cash ratio increased significantly in the 2000s: The 2010 ratio was almost twice as large as in 2000.

\section{Cross-Sectional Cash Holdings}

Previously we analyzed the evolution of cash holdings over time. In this section, we study how the distribution of the cash ratio is formed in the sample and how it varies between different 
Sánchez and Yurdagül

Figure 2

\section{Cash Ratio (Nonfinancial and Nonutility Firms)}

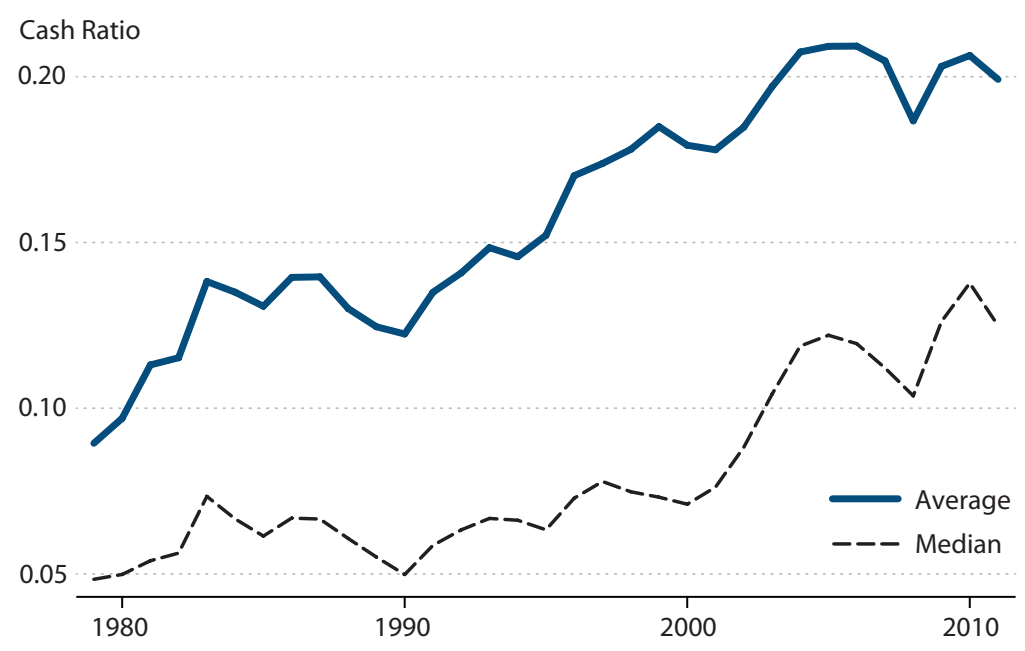

SOURCE: Compustat.

Figure 3

Distribution of Cash Ratio (Nonfinancial and Nonutility Firms)

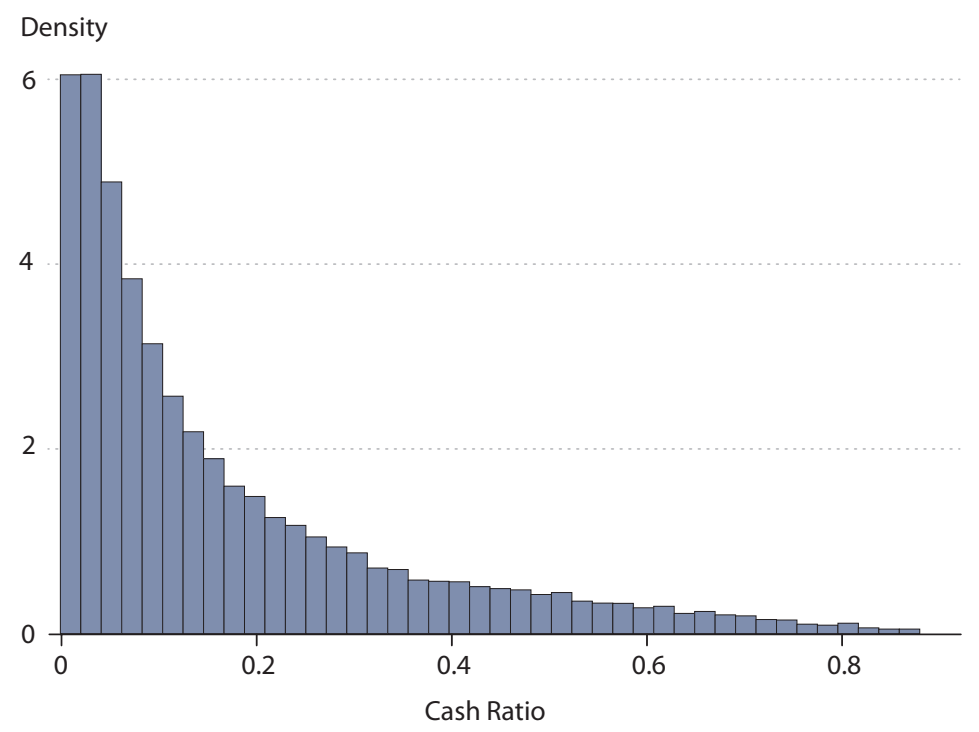




\section{Figure 4}

\section{Distribution of Cash Ratio by Sectors}
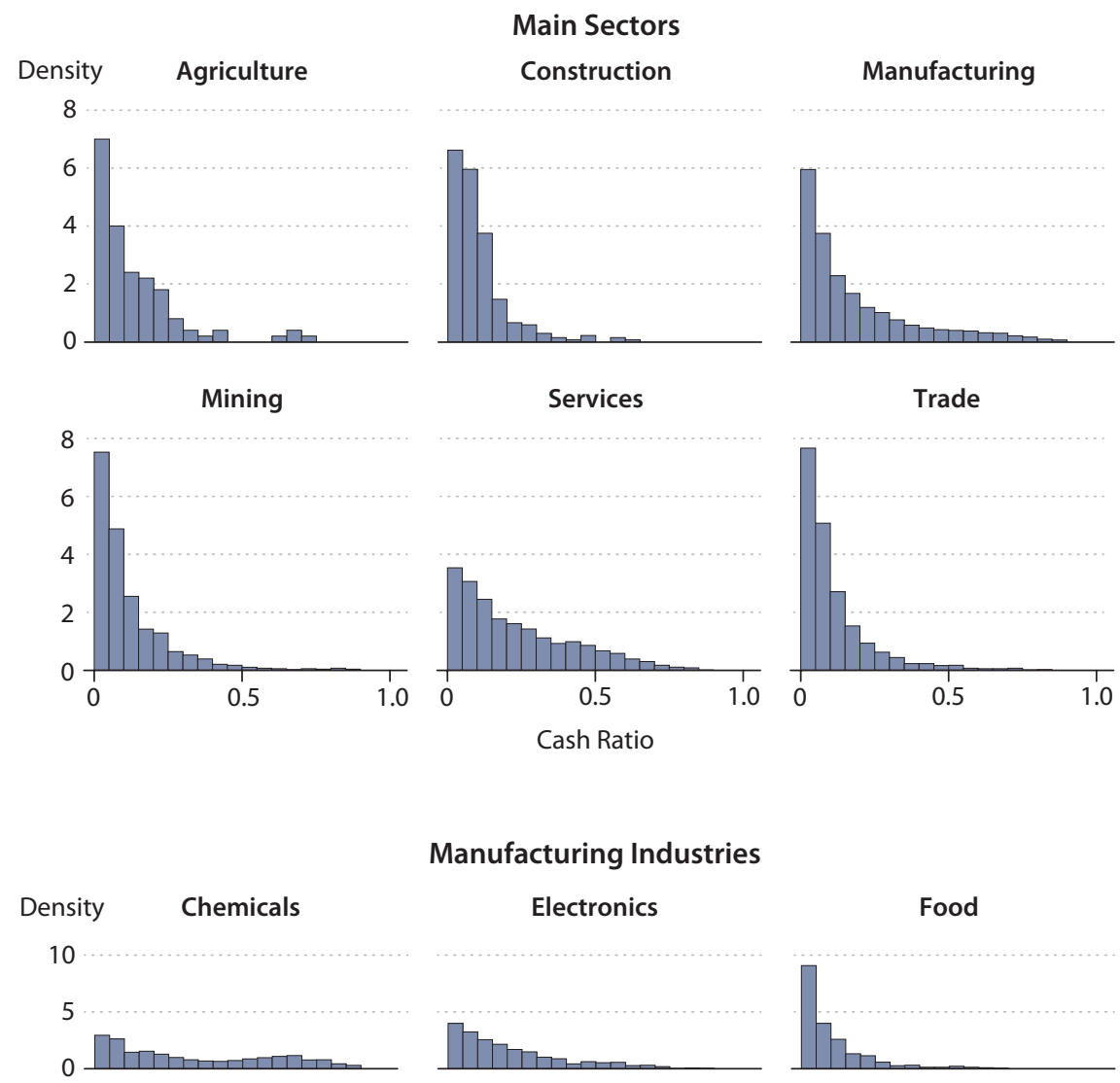

Manufacturing Industries

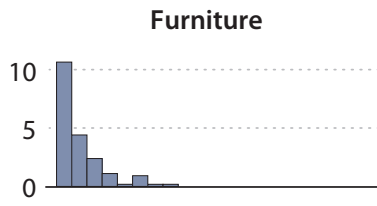

Petroleum Refining
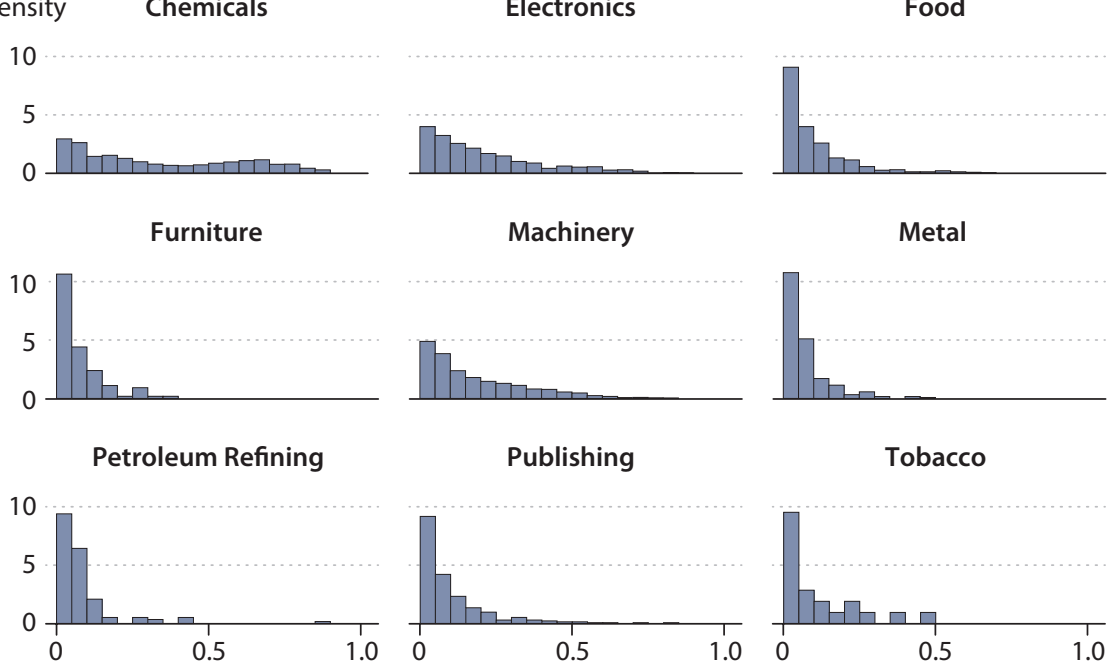

Publishing

Tobacco
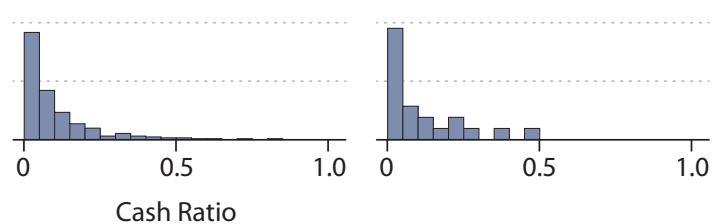


\section{Sánchez and Yurdagül}

groups of firms. A good approach to accomplish this and to abstract from the time dimension is to determine the mean cash ratio for each firm across time. Later we follow this approach to study other variables in cross sections of firms.

Figure 3 shows the cash ratio distribution in our sample. One observation is the fat right tail of the distribution, as there are many firms with cash ratios very close to zero and few firms with large cash holdings. In particular, 35 percent of the firms have an average cash ratio larger than 0.17 , which is the mean ratio in the sample. Figure 4 shows the cash ratio distribution for various broad sectors and industries in the economy. The sector with the most disperse distribution appears to be services. As a result, services has the highest mean cash ratio among these sectors: 0.23 . The sector with the next-highest ratio is manufacturing, with a mean cash ratio of 0.18. In line with these high cash ratios, these two sectors also have the highest standard deviation (SD) within the sectors in the top panel-both with 0.19 - while the overall sample has an SD of 0.18 .

There is also considerable heterogeneity within manufacturing; chemicals, electronics, and machinery have the flattest distributions and the highest means. Respectively, their average cash ratios are $0.33,0.21$, and 0.18 and SDs are $0.26,0.18$, and 0.16 .

\section{THE ROLE OF IDIOSYNCRATIC FACTORS}

In this section, we explore the importance of several factors in accounting for the cashholding patterns in the cross section of U.S. firms. For each of these factors, we construct a variable that captures its importance at the firm level. For instance, to evaluate the role of uncertainty, we construct the SD of the growth of total factor productivity at the firm level. Call this variable the proxy. Then we look at the correlation of the proxy variable with cash holdings. We do this at both the firm level and aggregating across sectors. We consider a positive correlation an indication that the factor represented by the proxy variable is important in accounting for crosssectional variations in cash holdings. Finally, to determine whether this factor may be important in accounting for the trend in cash holdings, we present the evolution over the past 20 years of the proxy variable together with the trend in cash holdings. If the factor under consideration is important in accounting for the recent rise in cash holdings, we would expect the trend of the proxy variable to be similar to that of cash holdings. $\underline{2}$

Notice that these are correlations, over time and in the cross section of firms, between two endogenous variables. Of course, the interpretation cannot be that the factors we consider caused cash holdings to increase. We use the correlations here to try to identify which groups in the population hold more cash and at what time. We think this information will be useful, for instance, in future research attempting to explain these trends with structural models.

We pursue the effects of the following factors on cash holdings: a firm's intensity in research and development $(\mathrm{R} \& \mathrm{D})$ activities, weight of foreign operations, rate of organizational expenditure, and volatility in firm activities. We also briefly discuss the literature proposing the importance of each of these factors. 


\section{Figure 5}

\section{Distribution of R\&D Intensity (Nonfinancial and Nonutility Firms)}

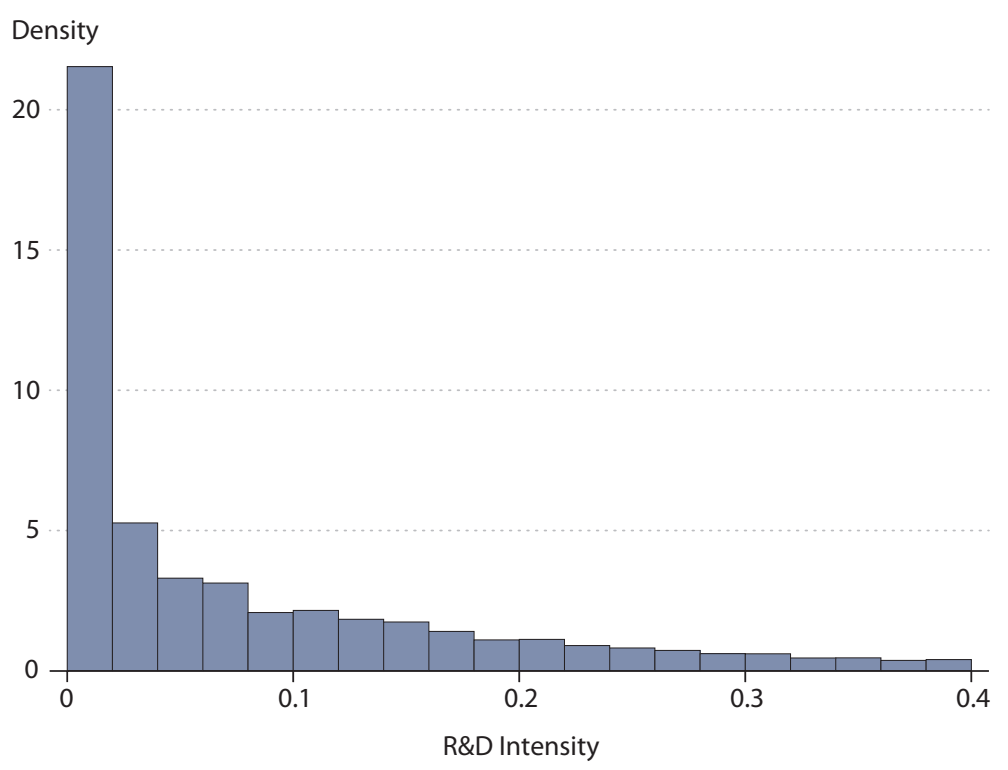

SOURCE: Compustat.

\section{Research and Development Intensity}

R\&D activities are strongly related to the cash holdings of firms because of the inherent uncertain nature of R\&D. Availability of projects does not follow a deterministic pattern and good investment opportunities can occur when firms' liquidity is tight. Hence, firms heavily involved in R\&D activities are likely to hold more cash than those that are less involved. In fact, Opler et al. (1999) argue that firms with stronger growth opportunities hold more cash and the cash ratio increases with their R\&D intensity. Moreover, in a recent article, Pinkowitz, Stulz, and Williamson (2012) confirm the same logic. They show that the recent abnormal cash holdings in the United States-the portion that cannot be predicted by the behavior in the late 1990scan largely be attributed to firms highly engaged in R\&D activities.

In this section, we explore the role of R\&D expenditures in the cash holdings of firms in our sample. We use the R\&D expenditures of firms relative to their size to gauge their intensity in research. In other words, the variable we construct to study how heavily firms invest in R\&D is

$$
R \& \text { DIntensity }_{i t}=\frac{R \& D \text { Expenditures }_{i t}}{\text { Assets }_{i t}} .
$$

Figure 5 shows the distribution of $R \& D$ intensity in our sample. The distribution is quite skewed: Only 33 percent of the firms have R\&D intensity larger than 0.10 , the mean ratio in the sample. The top panel of Figure 6 shows the distribution for six specific sectors (agriculture, 
Sánchez and Yurdagül

\section{Figure 6}

\section{Distribution of R\&D Intensity by Sectors}
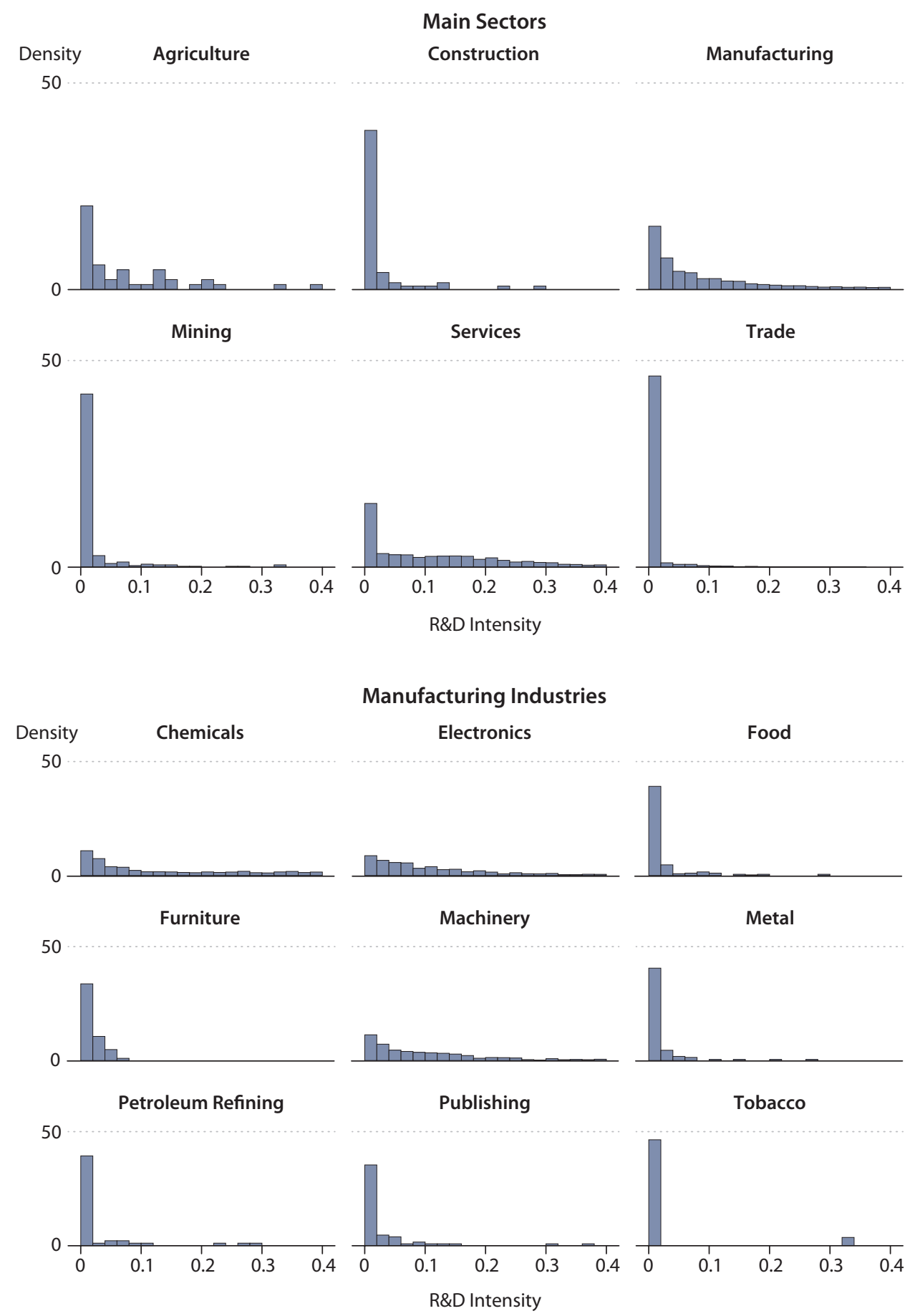

SOURCE: Compustat. 


\section{Figure 7}

\section{R\&D Intensity and Cash Ratio}
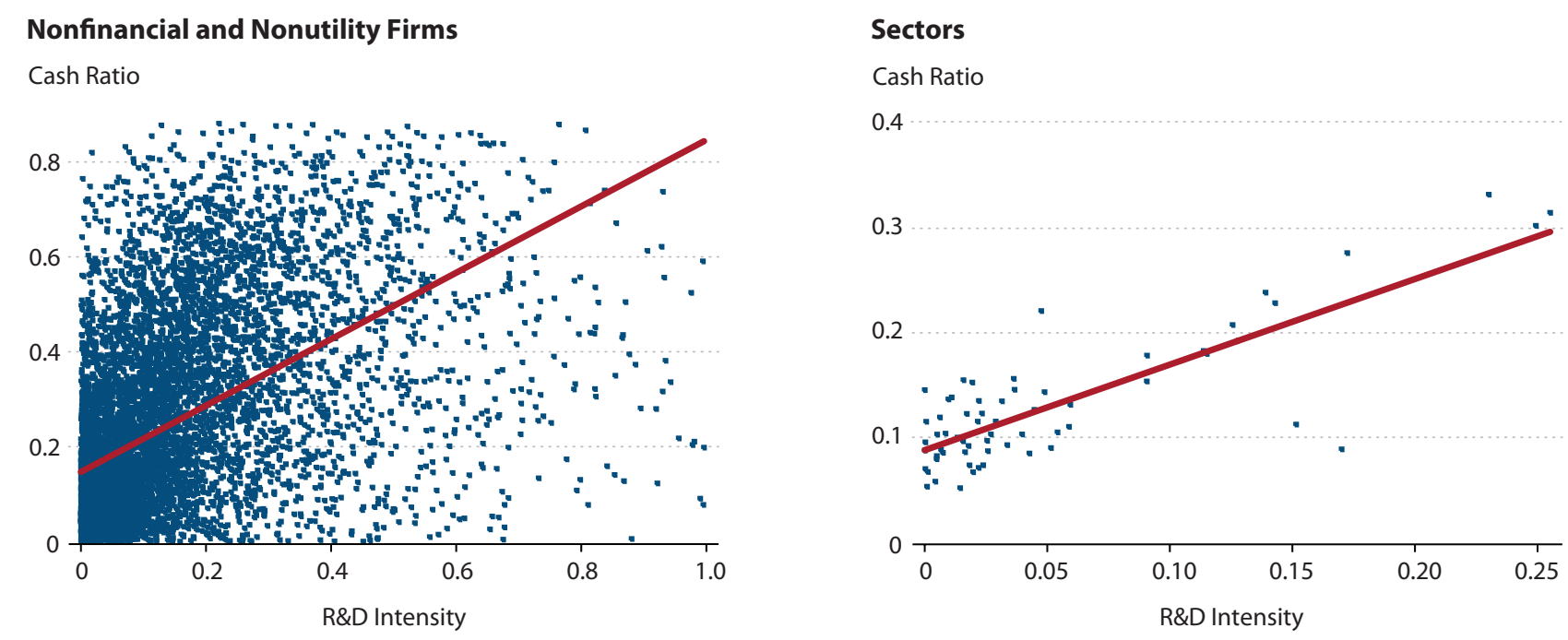

SOURCE: Compustat.

construction, manufacturing, mining, services, and trade). In most sectors, as in the overall sample, many firms have no R\&D expenditures. In some specific sectors, such as manufacturing and services, the distribution is more even - that is, in these sectors many firms are heavily involved in R\&D. The SDs of R\&D intensity for manufacturing and services are identical, 0.16 , while the SD for the whole sample is 0.15 . This trend is also reflected in the average R\&D expenditures-to-assets ratio. Among the six sectors, services has the highest mean, with 0.14 , and manufacturing has the second-highest, with 0.12 . The third sector (agriculture) has a much smaller share, with 0.08 . As shown in the bottom panel of Figure 6 , the manufacturing industries with widely spread distributions for this ratio are chemicals, electronics, and machinery, with average ratios of $0.23,0.13$, and 0.12 and SDs of $0.22,0.13$, and 0.13 , respectively.

Recall that the sectors with the highest average cash ratio are services and manufacturing; the corresponding industries within manufacturing are chemicals, electronics, and machinery. These are also the industries invested more heavily in R\&D.

Figure 7 provides a second demonstration of the association between cash and R\&D activities. The left panel plots the mean cash ratio for each firm (across time) against mean R\&D intensity. The obvious positive correlation between the two variables holds if firms are collapsed into their two-digit Standard Industrial Classification (SIC) sectors (see the right panel of Figure 7). One two-digit sector in the upper-right corner of the graph with R\&D intensities higher than 0.2 and a cash ratio higher than 0.3 is chemicals (in the manufacturing sector), and the other two are membership organizations and miscellaneous services (in the services sector).

Since our main goal is to identify factors that could account for the increase in cash holdings, it is useful to consider the time series of R\&D expenditures. Figure 8 shows the behavior of 


\section{Figure 8}

\section{R\&D Intensity (Nonfinancial and Nonutility Firms)}
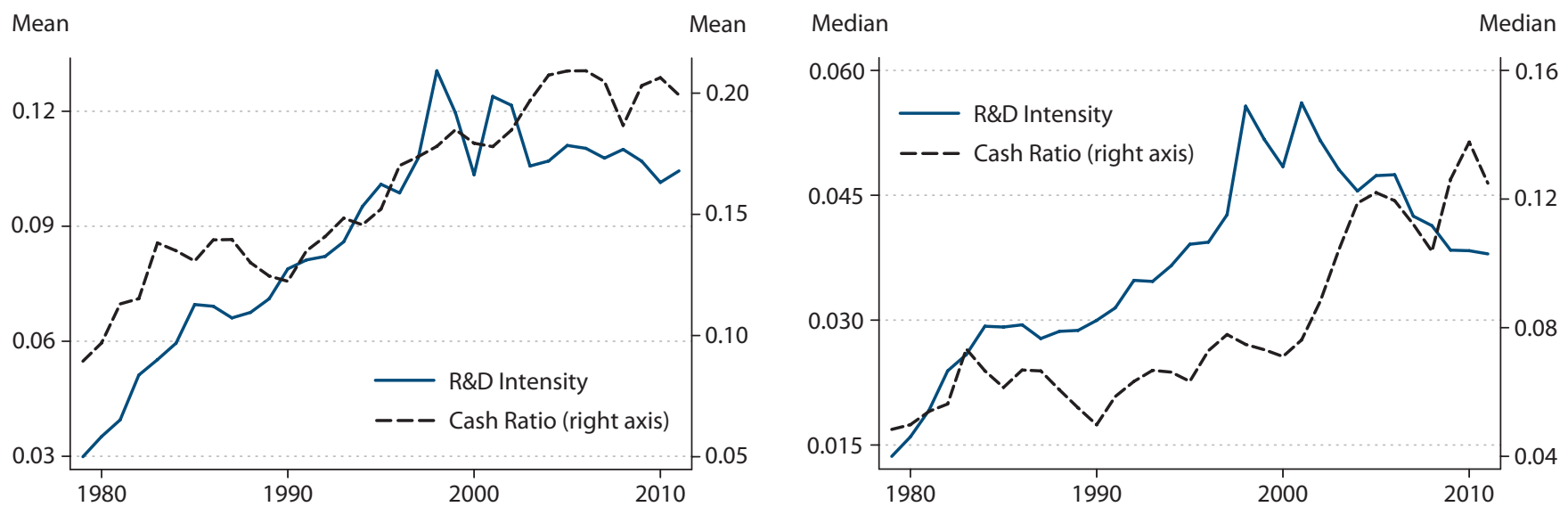

SOURCE: Compustat.

R\&D expenditures compared with the cash ratio; means are shown in the left panel and medians in the right panel. $\underline{3}$ The figure shows that R\&D intensity did indeed increase from the 1980s until the late 1990s. In particular, the annual growth rate of R\&D intensity from 1979 to 1998 was around 8 percent for both the mean and the median, which is consistent with the trend in the cash ratio for this interval. Conversely, Figure 8 shows the mean and median R\&D intensity for the sample was stagnant over the past decade rather than exhibiting the increasing pattern of the cash ratio. In fact, from 1998 to 2011 the annual rate of decline in the mean R\&D intensity is 2 percent; for the median, this rate is 3 percent. If the flow of $R \& D$ expenditures is the basis for the recent increase in the stock of cash holdings, we would expect to see increased firm R\&D intensity over the same period.

The main point we hoped to convey in this section is that R\&D seems important for cash holdings in the cross section of firms. On the other hand, the decreasing trend for this variable over the past decade does not match well with the increase in the cash ratio. This mismatch suggests that although R\&D intensity is closely related to the cash ratio in the cross section of firms, it cannot account for the recent trend in cash holdings.

\section{Foreign Income Ratio}

Firms that operate heavily abroad may have an additional motivation for cash holding: the tax burden associated with repatriating foreign earnings. In particular, Foley et al. (2007) show this association empirically and argue that firms that would incur more costs by repatriating foreign earnings hold more cash.

Following a similar logic, we study the relationship between the weight of foreign operations in firms' activities and their cash-holding behavior. The variable of focus here is the ratio of pretax foreign income of firms to their total assets: 


\section{Figure 9}

\section{Distribution of Foreign Income Ratio (Nonfinancial and Nonutility Firms)}

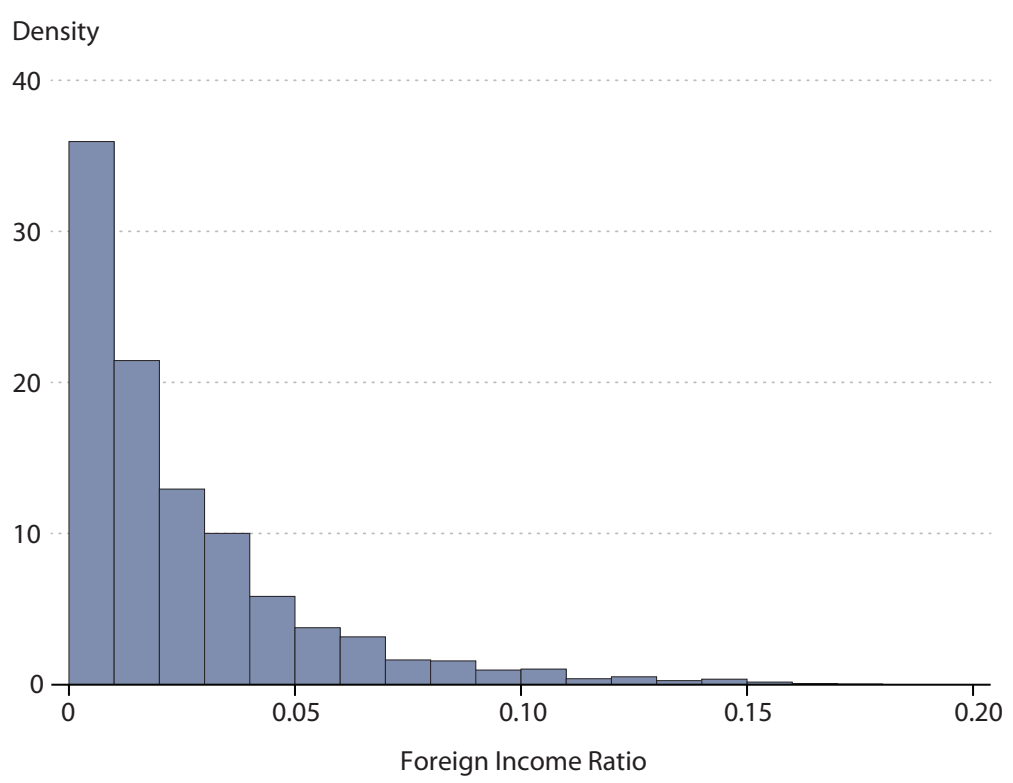

SOURCE: Compustat

$$
\text { ForeignIncomeRatio }_{i t}=\frac{\text { ForeignIncome }_{i t}}{\text { Assets }_{i t}} .
$$

As with the R\&D intensity, we start by showing the overall distribution of this variable (Figure 9) and do the same for different sectors in the sample (Figure 10, top panel) and industries within manufacturing (Figure 10, bottom panel). As before, there is a concentration near zero in the overall sample. In fact, only 43 percent of the firms have a foreign income ratio larger than 0.01 , which is the mean in the sample. In terms of the increased density of the distribution near zero, the heterogeneity across sectors and industries that appears for R\&D intensity is absent for the intensity of foreign operations. The mean foreign income ratio for all sectors is between 0.02 (construction, services, and trade) and 0.04 (agriculture), and the sector-specific $\mathrm{SD}$ is also between 0.02 and 0.04 . The range of means within the manufacturing sector is limited between 0.01 (publishing) and 0.04 (petroleum refining).

The left panel of Figure 11 shows the relation between the cash ratio and foreign activity across firms. If firms do not repatriate cash earned overseas, we would expect to see a strong positive correlation between the cash holdings ratio and foreign income ratio. There is a positive correlation, but it is not as strong as for the R\&D intensity. The corresponding graph for twodigit sectors illustrates the same relation (Figure 11, right panel). Although the correlation in this grouping seems more significant, it is mostly due to the vaguely defined two-digit sector of miscellaneous services. 


\section{Figure 10}

\section{Distribution of Foreign Income Ratio by Sectors}

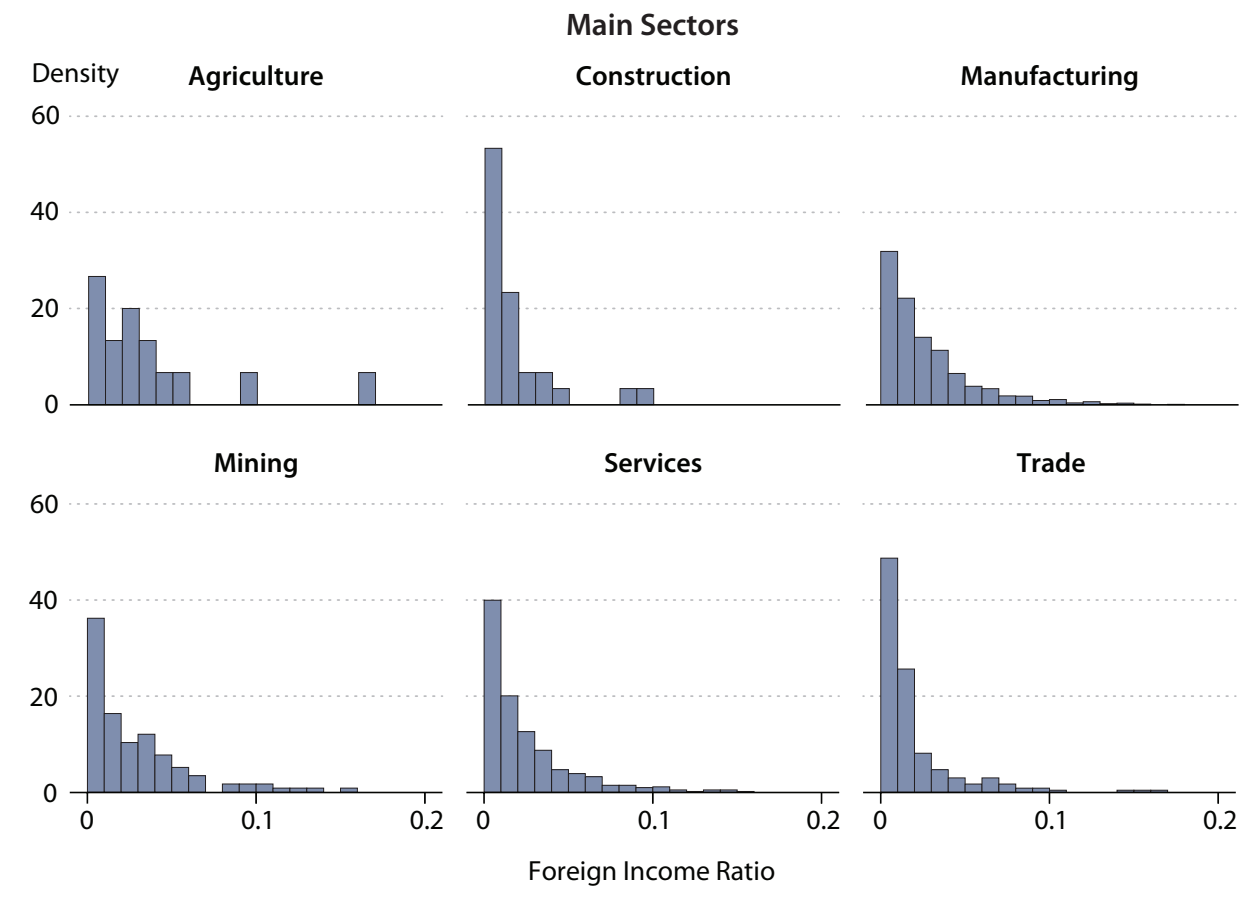

Manufacturing Industries

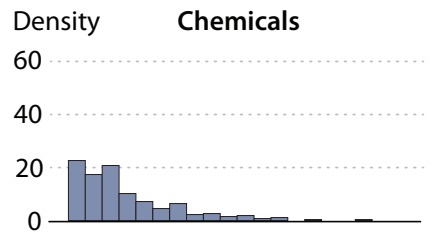

Furniture

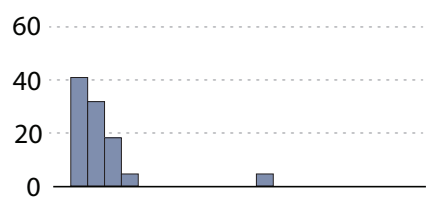

Petroleum Refining

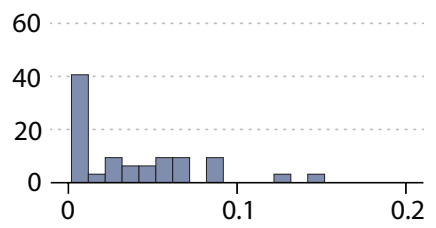

Electronics

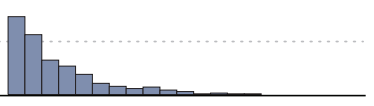

Machinery

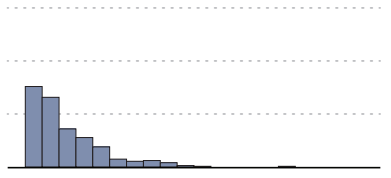

Publishing

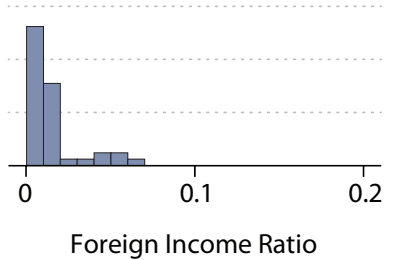

Food

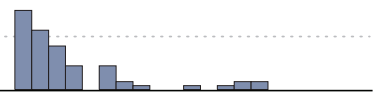

Metal

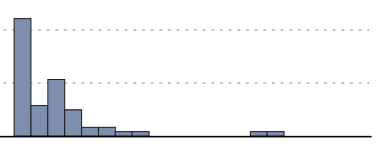

Tobacco

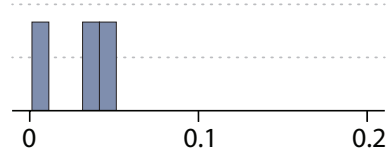

SOURCE: Compustat. 


\section{Figure 11}

\section{Foreign Income Ratio and Cash Ratio}

\section{Nonfinancial and Nonutility Firms}

Cash Ratio

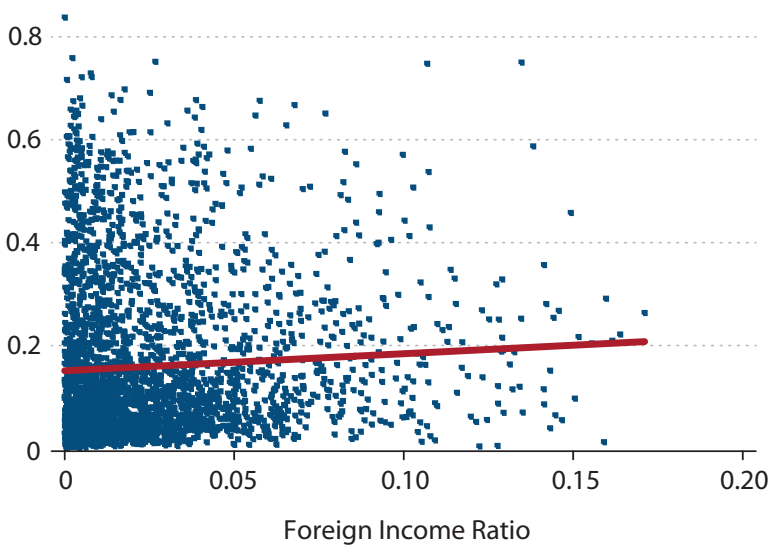

\section{Sectors}

Cash Ratio

0.4

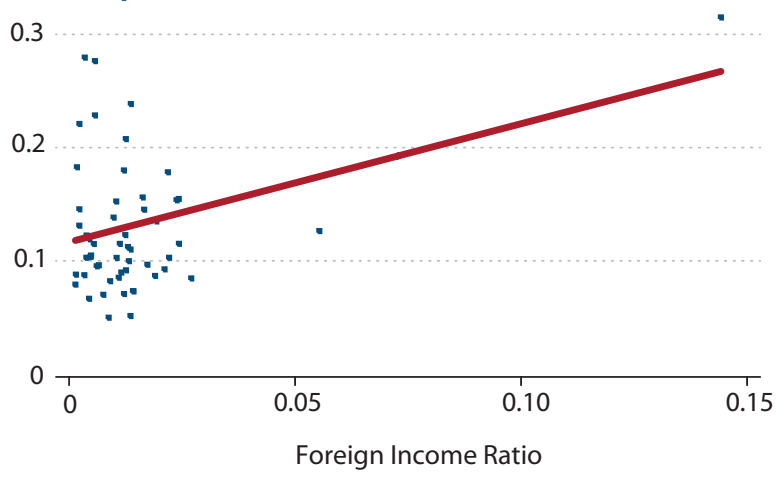

Figure 12

\section{Foreign Income Ratio (Nonfinancial and Nonutility Firms)}
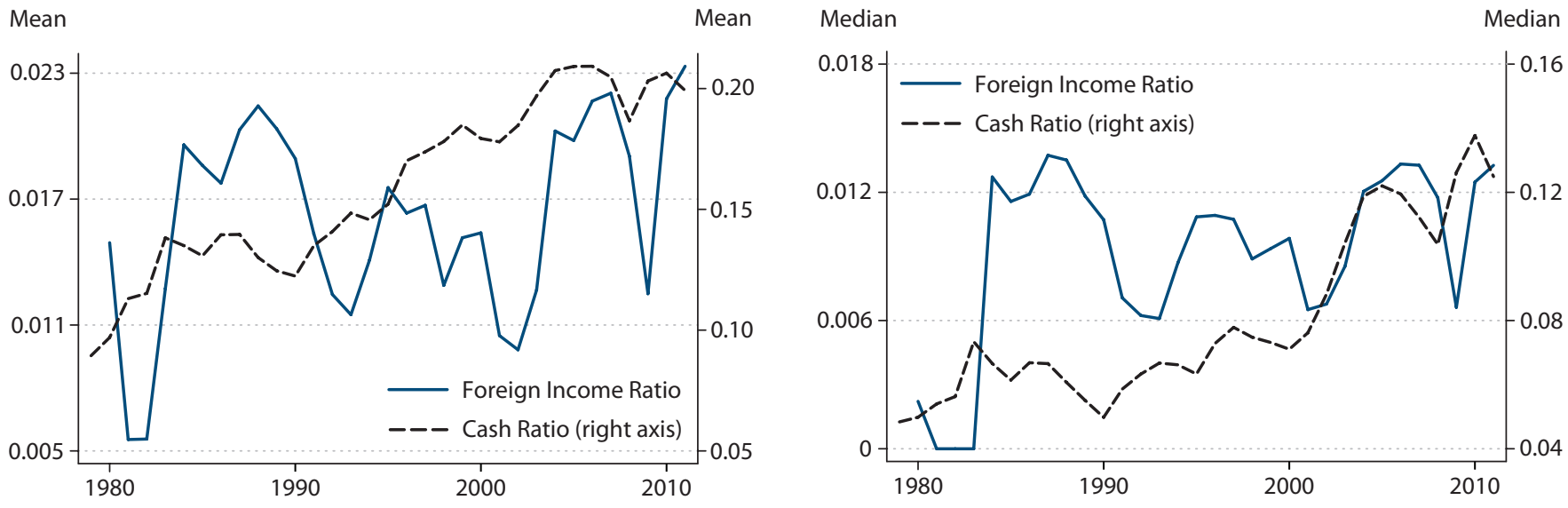

SOURCE: Compustat. 


\section{Sánchez and Yurdagül}

Figure 12 illustrates the time series of the foreign income ratio; the left panel corresponds to the mean and the right panel to the median foreign income ratio. If firms do not repatriate cash earned overseas, the cash ratio should increase faster when the foreign income ratio is higher. The evolution of these statistics does not exhibit the clearly increasing behavior of the cash ratio. For instance, from 1990 to 2000, the mean foreign income ratio lacks a persistent slope, while the cash ratio has a clearly positive trend (Figure 12, left panel).

In short, although certain similarities exist between the behavior of the foreign income ratio and cash holdings for the past 10 years, the foreign income ratio in the late 1980s is very similar to that in the 2000s. In addition, the correlation in the cross section of firms is weak, indicating that firms with higher cash ratios are not necessarily those that are more active in foreign operations. Thus, it seems difficult to conclude that the recent rise in cash holdings is an outcome of more firms heavily involved in activities abroad.

\section{Organizational Expenditure Rate}

The efficiency of a firm in using its resources (such as human and physical capital) and its capability for future growth depend highly on its current knowledge base and organizational efficiency. Such stock is what we consider as a firm's organizational capital, which scholars have defined in various ways. $\underline{4}$

Since organizational capital is closely connected to the future growth and investment opportunities of a firm, it may be naturally linked to cash holdings. In fact, Speckbacher and Wentges (2009) argue that "from the management's point of view, high corporate cash holdings allow investments in organizational capital even in periods with poor operating cash flows" (p. 55).

We construct a measure of the organizational expenditure rate as follows ${ }^{5}$ :

$$
\text { OrganizationalExpenditureRate }_{i t}=\frac{\text { OrganizationalExpenditures }_{i t}}{\text { Assets }_{i t}} .
$$

Figures 13 and 14 illustrate the distribution of this statistic in the sample. The overall distribution is concentrated in values close to zero. Across sectors, there is considerable heterogeneity; services, trade, and manufacturing have much more widely spread distributions than the other sectors. The SDs within these sectors are $0.43,0.35$, and 0.35 , respectively. The mean organization expenditure rates for services, trade, and manufacturing, the highest three in the list, are 0.55 , 0.51 , and 0.43 , respectively. Within manufacturing, the chemicals industry has the highest mean of 0.54 and the flattest distribution. Notice that these groups of firms roughly coincide with those with the highest cash ratios.

Figure 15 more clearly illustrates the positive correlation between the organizational expenditure rate and cash holdings. One example is the outlier two-digit industry membership organizations (shown in the right panel), with an organizational expenditure rate of 0.94 and an average cash ratio of 0.30 . The path of this variable across time is qualitatively similar to the R\&D intensity. The left panel of Figure 16 shows the evolution of the mean, and the right panel shows that of the median of this ratio compared with the pattern for the cash ratio. A sharp increase occurs in the organizational expenditure rate from the beginning of the sample to 2001. The yearly growth rate from 1979 to 2001 is around 1 percent for both the mean and the median. Never- 


\section{Figure 13}

\section{Distribution of Organizational Expenditure Rate (Nonfinancial and Nonutility Firms)}

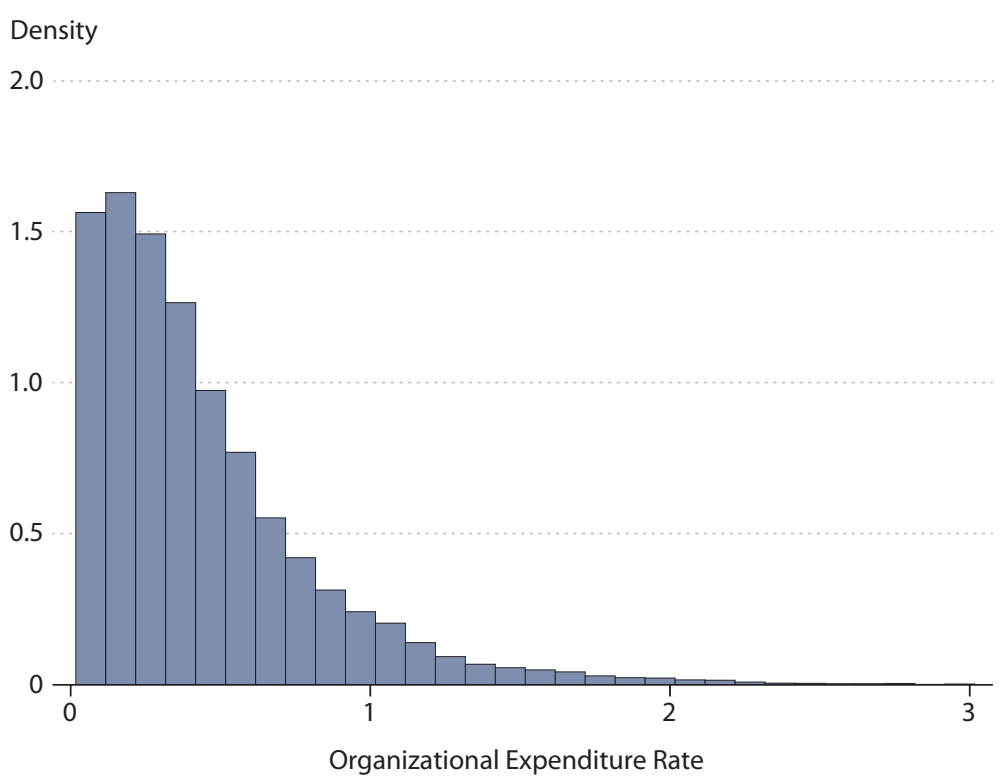

SOURCE: Compustat.

theless, during the 2001-11 period, organizational expenditure declines at an annual rate of around 3 percent for both statistics.

Analysis of the cross section of firms shows a positive correlation between the organizational expenditure rate and the cash ratio. However, the organizational expenditure rate does not have an increasing pattern comparable to that of the cash ratio for the past decade. Hence, it seems unlikely that the organizational expenditure rate is a major factor in accounting for the rise in cash holdings over the past decade.

\section{Volatility}

Uncertainty associated with firms' activities may require them to hoard cash for various reasons. Not only will a bad productivity shock affect a firm's cash flow, implying the need for liquid assets, but it is also likely that good shocks boosting the firm's productivity or sales necessitate investment, which requires resources to undertake.

Bates, Kahle, and Stulz (2009) show that the groups of firms with major increases in cash ratios are in industries with the highest increases in idiosyncratic volatility. They conclude that the precautionary motive is important in accounting for higher cash holdings.

In this section, we examine how instability and unpredictability at the individual variable level are related to firms' cash holdings. In particular, we focus on firms' productivity, sales, and cash flow. We construct a measure of volatility for each variable using the variation in the corresponding growth rates. 


\section{Figure 14}

\section{Distribution of Organizational Expenditure Rate by Sectors}
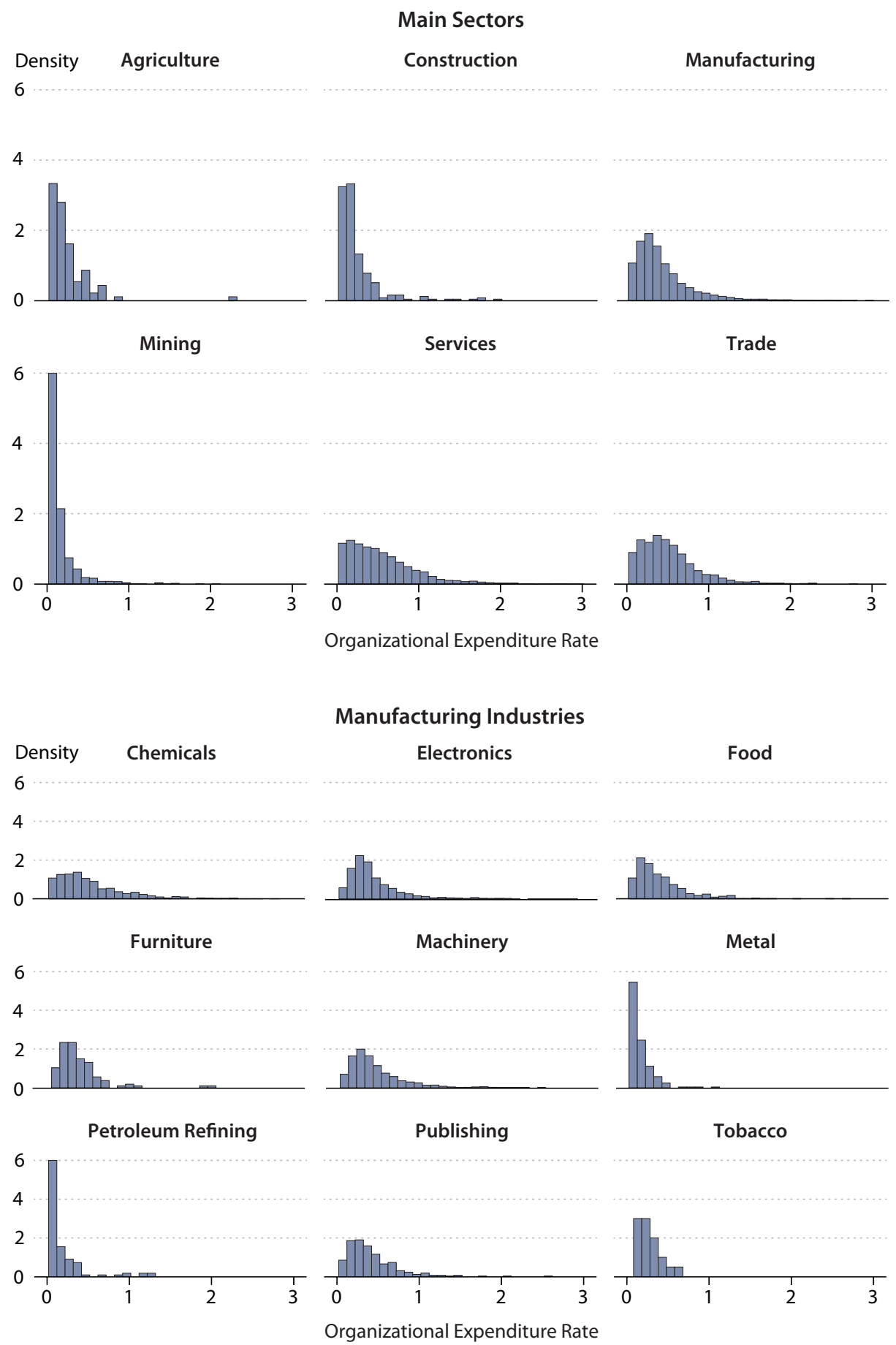

SOURCE: Compustat. 


\section{Figure 15}

\section{Organizational Expenditure Rate and Cash Ratio}

\section{Nonfinancial and Nonutility Firms}

Cash Ratio

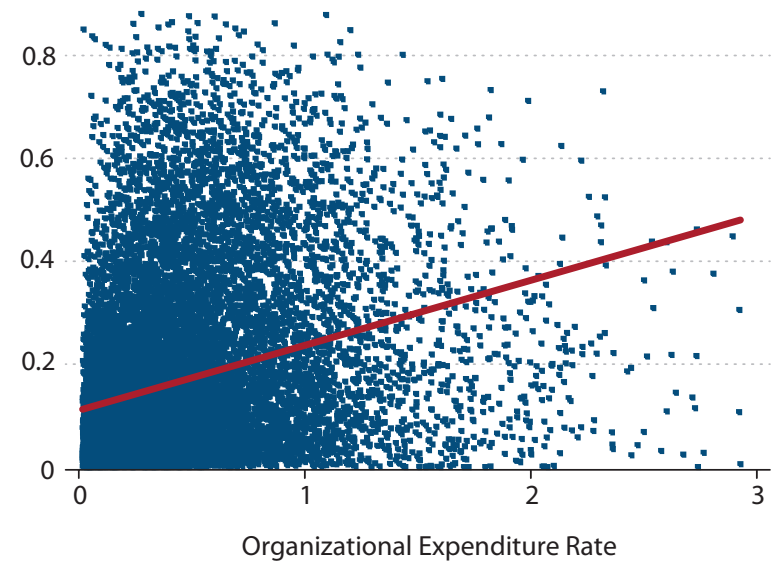

\section{Sectors}

Cash Ratio

0.4

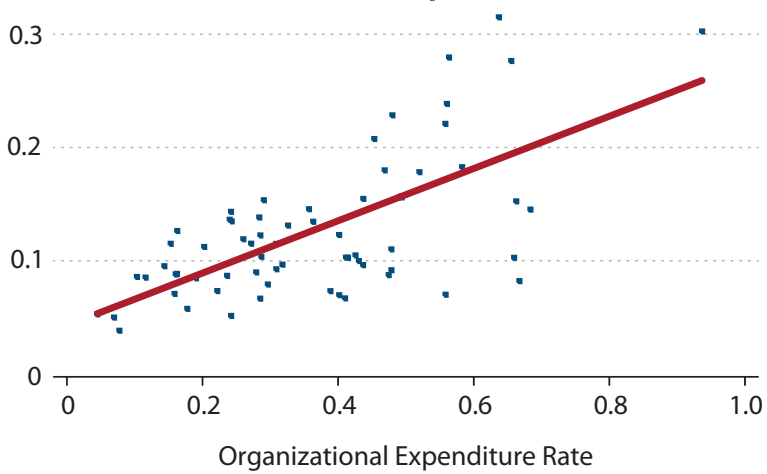

Figure 16

\section{Organizational Expenditure Rate (Nonfinancial and Nonutility Firms)}
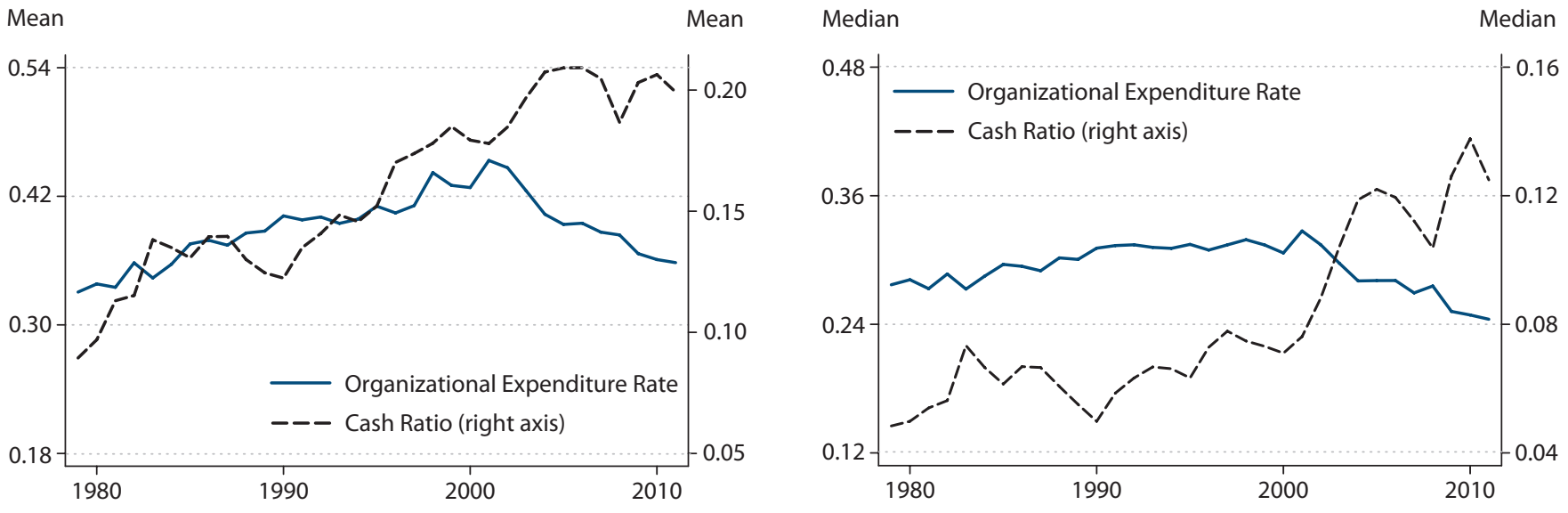

SOURCE: Compustat. 


\section{Sánchez and Yurdagül}

While all three variables used to measure volatility are closely related, it is useful to present different measures to check the robustness of our results. For all analyses, we use growth rates rather than levels to eliminate the effects of trends. Continuation of a trend (increasing or decreasing) is likely to be anticipated and hence less likely to motivate cash holdings. More relevant in this context is the extent of firm-specific variation in the pattern of growth rates for these variables.

In constructing the proxy variables for this section, we assume that firms learn from past experiences. They think that large variations in growth of productivity, sales, and cash flows are possible, and they save cash for that eventuality only if they have experienced such variations in the recent past.

Productivity Volatility. One variable potentially correlated with cash holding is firm-level productivity volatility. We capture productivity by using the residual in the linear regression of the logarithm of operating income on the logarithm of the firm's capital stock:

$$
\log (\text { OperatingIncome })_{i t}=\beta_{0}+\beta_{1} \log (\text { Capital })_{i t}+\varepsilon_{i t} \text {. }
$$

The assumption that firms know this relationship is our reason for running this regression and using variations in the error term to represent uncertainty. Thus, deviations from this relationship are good proxies for surprises. Correspondingly, we define the productivity growth as the change in the residuals of this estimation from the previous year. In turn, the firm-specific volatility in productivity is the SD of this growth rate across the past nine observations of a firm $\underline{6}$; that is,

$$
\text { Productivity Volatility }_{i t}=\frac{1}{8} \sum_{j=t-8}^{t}\left(g_{i j}-\bar{g}_{i}^{(t)}\right)^{2} \text {, }
$$

where

$$
\begin{gathered}
\bar{g}_{i}^{(t)}=\frac{1}{9} \sum_{j=t-8}^{t} g_{i j}, \\
g_{i t}=\varepsilon_{i t}-\varepsilon_{i t-1},
\end{gathered}
$$

and $\varepsilon_{i t}$ is the residual in the previous regression.

Figures 17 and 18 illustrate the productivity volatility distribution in the sample. Most sectors show high concentrations of low volatility accompanied by a fat right tail. For the overall sample, 63 percent of the firms have volatility smaller than the mean of 0.47 . At the same time, volatility for some sectors and industries is less concentrated close to the zero point. Across sectors, the volatility distribution for construction is the most evenly spread, with a mean of 0.65 ; the nextclosest sector is mining, with an average volatility of 0.54 . Within manufacturing, with an average volatility of 0.49 , the metal industry has the highest overall volatility with a mean of 0.62 .

As with $\mathrm{R} \& \mathrm{D}$ or foreign operations intensity, volatility in productivity is positively correlated with cash holdings in the cross section of firms. However, the aggregate data over two-digit sectors shows a smaller correlation (Figure 19). Industries such as legal services (with a cash ratio more than 0.27 and productivity volatility of 0.2 ) and building construction general contractors and operative builders (with a cash ratio lower than 0.1 and productivity volatility as high as 0.7 ) keep the sector-wise correlation from being more positive. 


\section{Figure 17}

\section{Distribution of Productivity Volatility (Nonfinancial and Nonutility Firms)}

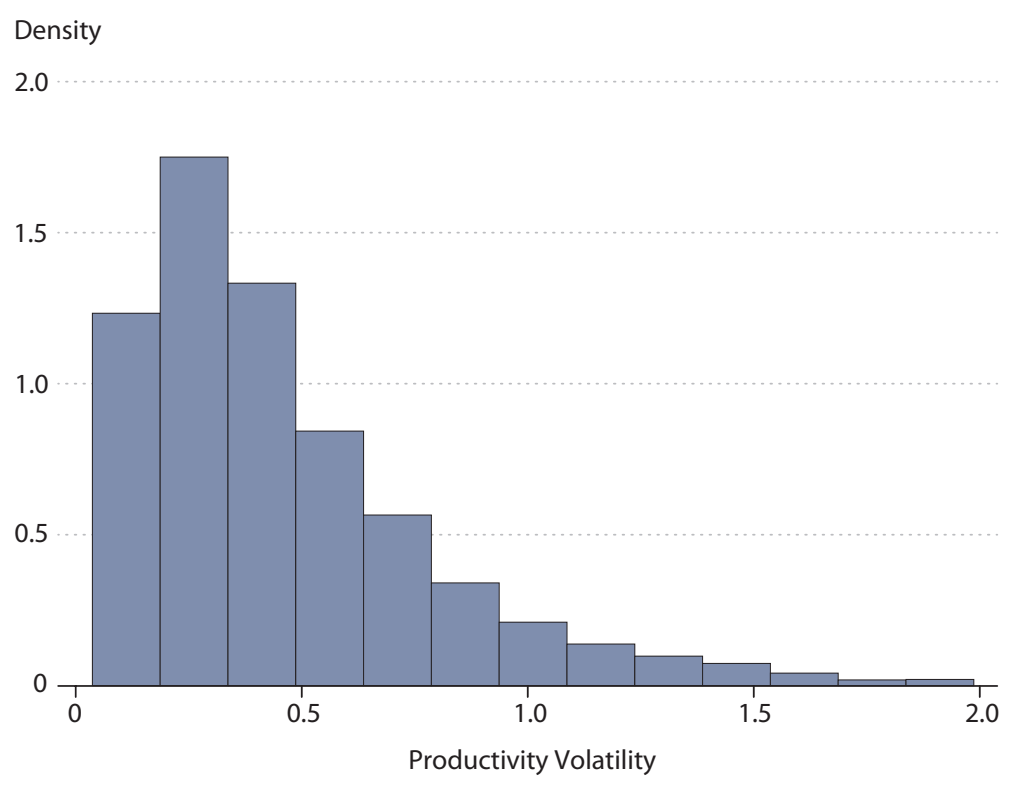

SOURCE: Compustat.

Figure 20 shows the time series of this productivity volatility. - With this simple measure of volatility, the absence of a long-lasting increasing trend in the study period is noticeable. If anything, there is a decrease with an annual rate near 1 percent for both means and medians.

In a nutshell, this measure of volatility exhibits strong positive correlation with the cash ratio in the cross section of firms, while an increasing recent trend to accompany the recent pattern in cash holdings is missing. Thus, it seems difficult to argue that idiosyncratic risk in productivity can account for the recent trend in cash holdings.

Sales Volatility. In this section, we construct a measure of firm-specific volatility using sales. In particular, we focus on the SD of the change in the logarithm of sales within the past nine observations for a firm:

$$
\text { Sales Volatility }{ }_{i t}=\frac{1}{8} \sum_{j=t-8}^{t}\left(d_{i j}-\bar{d}_{i}^{(t)}\right)^{2} \text {, }
$$

where

$$
\begin{aligned}
& \bar{d}_{i}^{(t)}=\frac{1}{9} \sum_{j=t-8}^{t} d_{i j}, \text { and } \\
& d_{i t}=\log (\text { Sales })_{i t}-\log (\text { Sales })_{i t-1} .
\end{aligned}
$$




\section{Sánchez and Yurdagül}

\section{Figure 18}

\section{Distribution of Productivity Volatility Rate by Sectors}

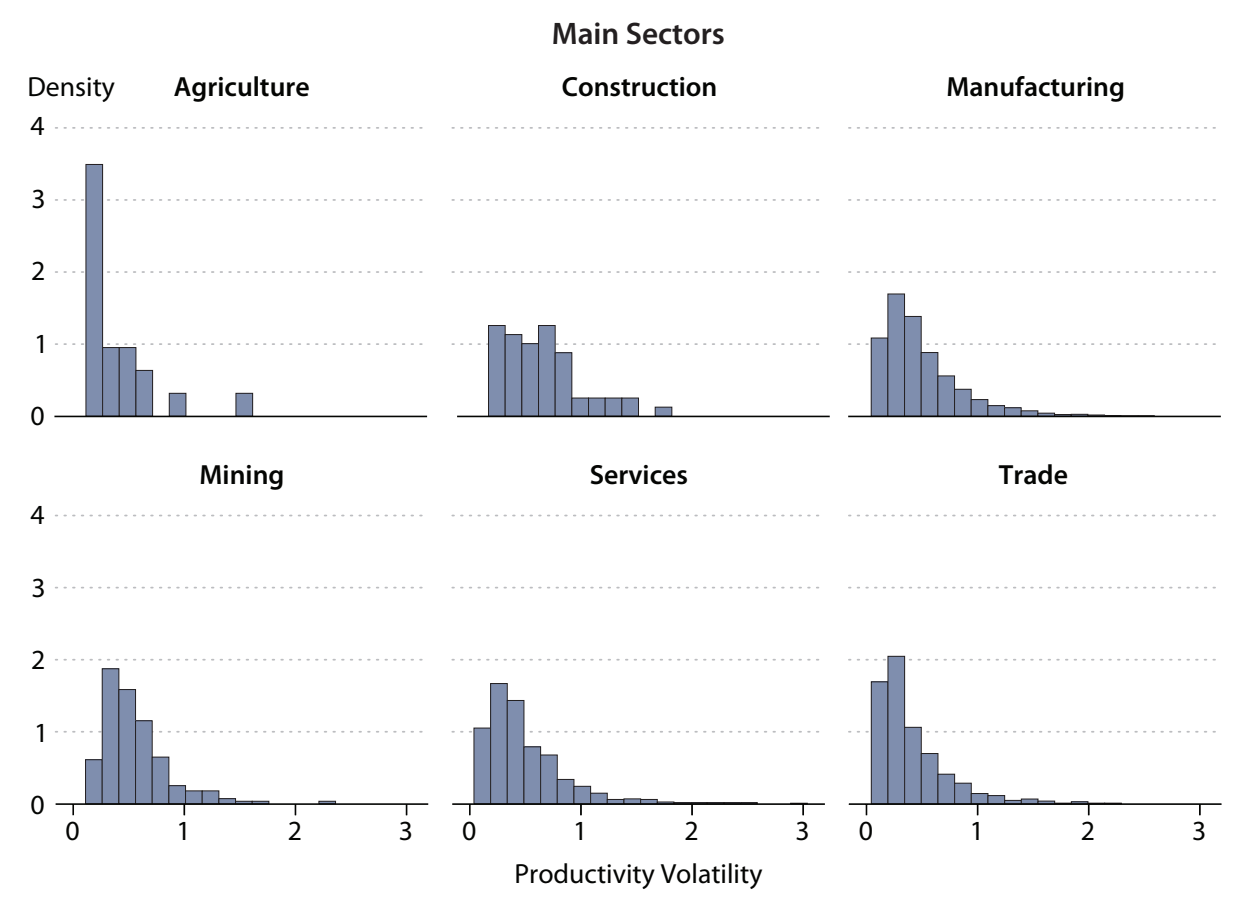

Manufacturing Industries

$\begin{array}{llll}\text { Density } & \text { Chemicals } & \text { Electronics } & \text { Food } \\ 5\end{array}$
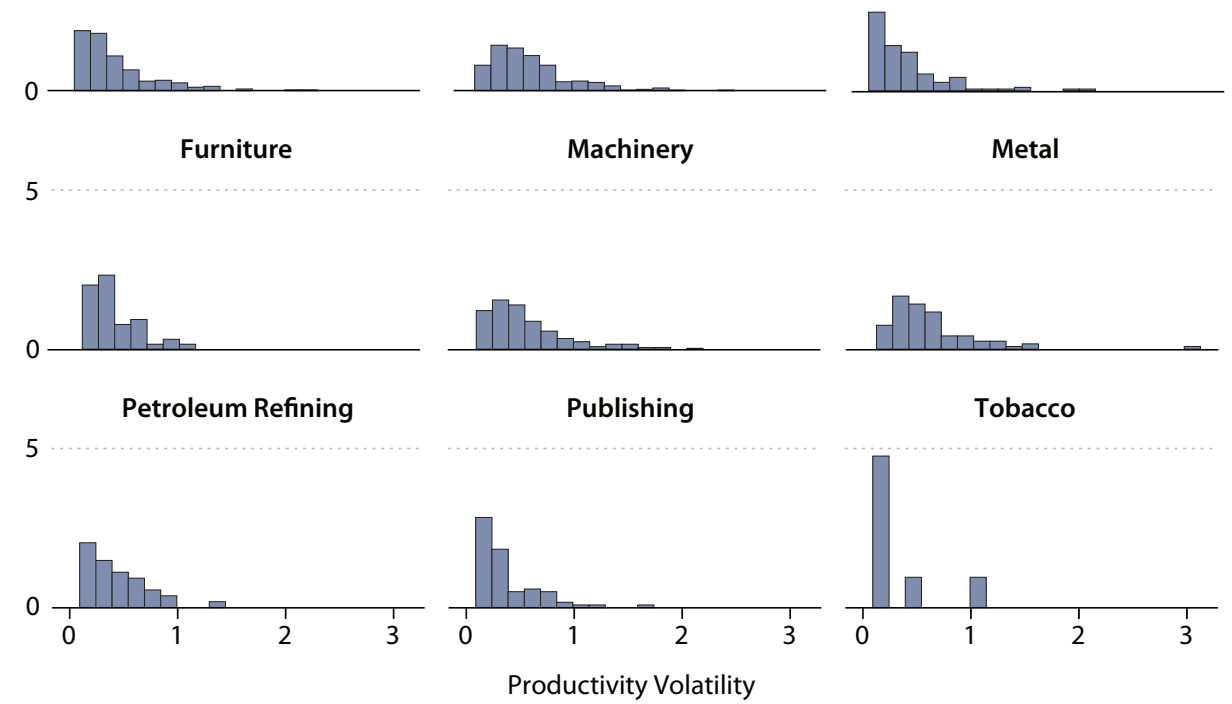

SOURCE: Compustat. 


\section{Figure 19}

\section{Productivity Volatility and Cash Ratio}

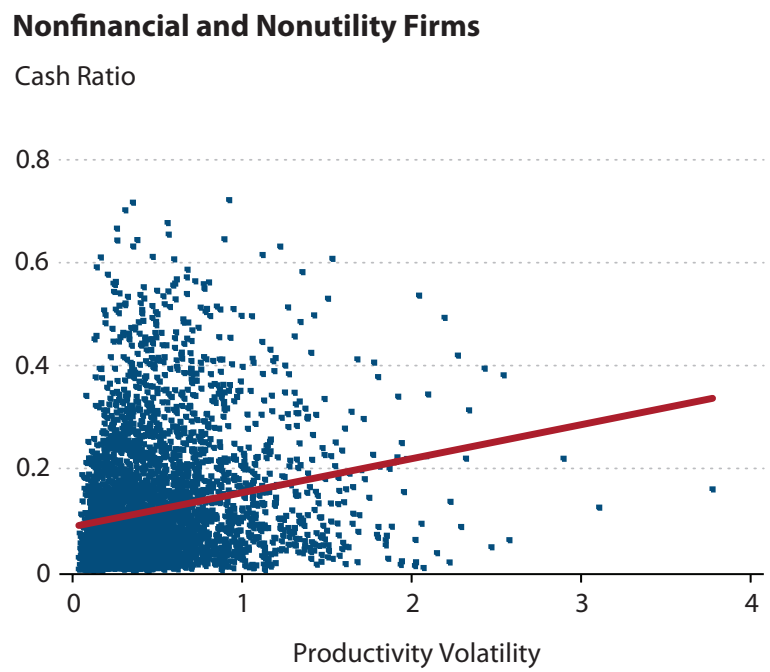

\section{Sectors}

Cash Ratio

0.4

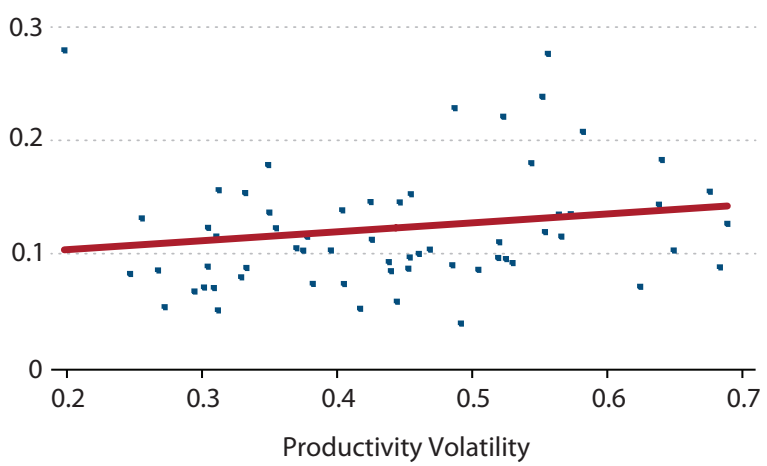

SOURCE: Compustat.

Figure 20

\section{Productivity Volatility (Nonfinancial and Nonutility Firms)}
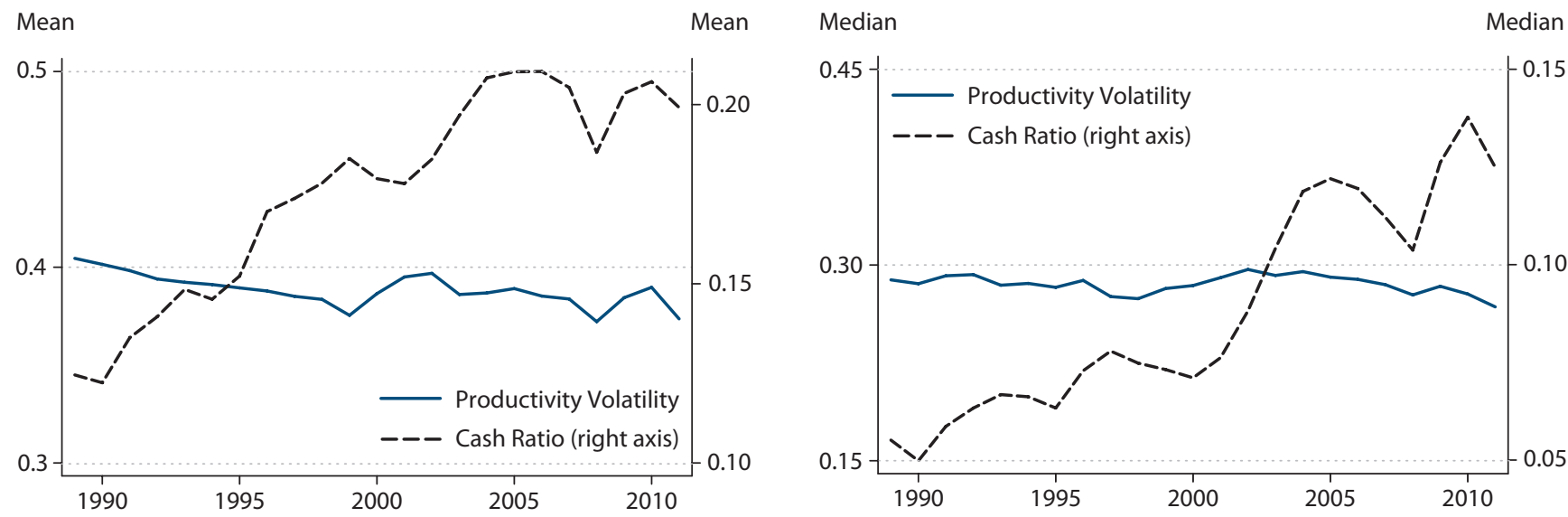

SOURCE: Compustat. 


\section{Figure 21}

\section{Distribution of Sales Volatility (Nonfinancial and Nonutility Firms)}

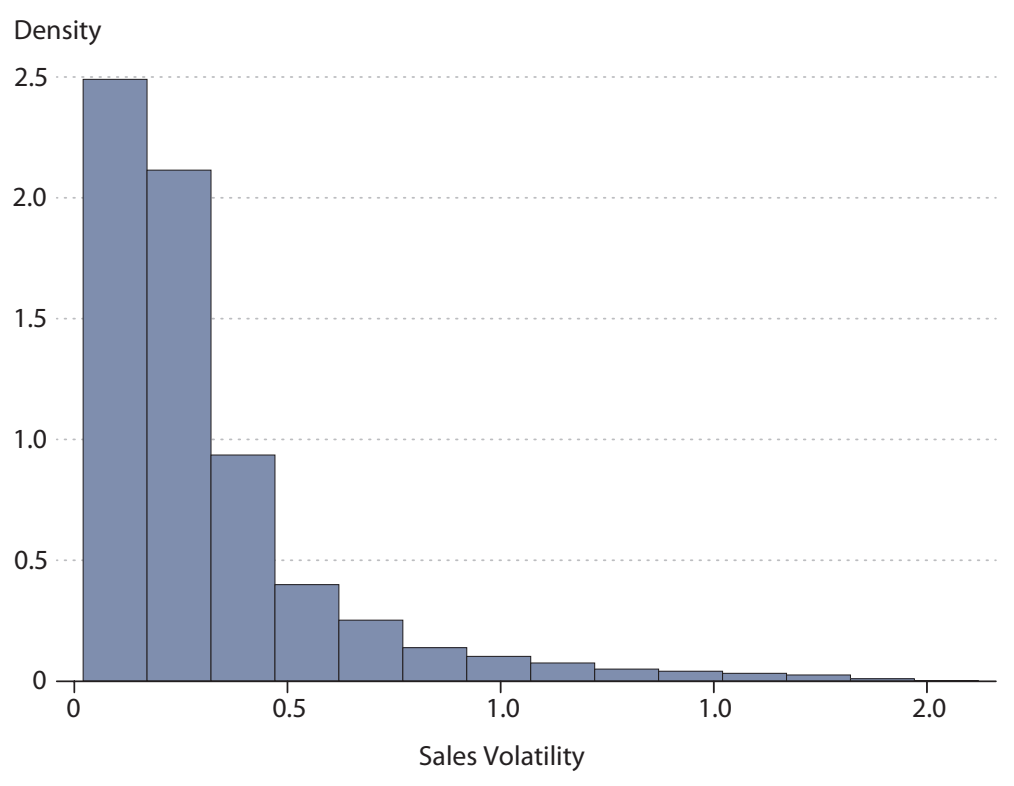

SOURCE: Compustat.

Figure 21 shows the distribution of sales volatility throughout the firms in the sample. In addition to the fat right tail, the similarity of this distribution to the distribution of productivity volatility is noticeable. For this measure, volatility is lower than the mean of 0.33 for 69 percent of firms. According to this measure, the mining sector has the highest volatility, with an average of 0.49 , which can be seen by observing the less-concentrated distribution for this group near zero (Figure 22, top panel). Meanwhile, some sectors have higher SDs than mining (0.35) (e.g., manufacturing, 0.37). The bottom panel of Figure 22 shows that within the manufacturing sector, which has a mean ratio of 0.33 , the chemicals industry has the highest average volatility, with a mean of 0.53 , and the flattest distribution.

As with the volatility in productivity, there is a positive correlation between sales volatility and cash holding at the firm level (Figure 23, left panel). The right panel shows a positive correlation across two-digit sectors, even though this association appears less significant in the linear fit, partially because of the low cash ratio of forestry (0.08) accompanied by high sales volatility (0.73).

Figure 24 shows the evolution in sales volatility over time, with an increase until 2002, followed by stagnation and then a decline in the past 5 years. This pattern suggests that uncertainty may account for the rise in cash holdings until the early 2000s, but it cannot be associated with the evolution of cash holdings over the past decade.

Cash Flow Volatility. In addition to the indicators previously discussed, another-and perhaps more direct—-way to study the relationship between cash holding and volatility in firms' 


\section{Figure 22}

\section{Distribution of Sales Volatility Rate by Sectors}
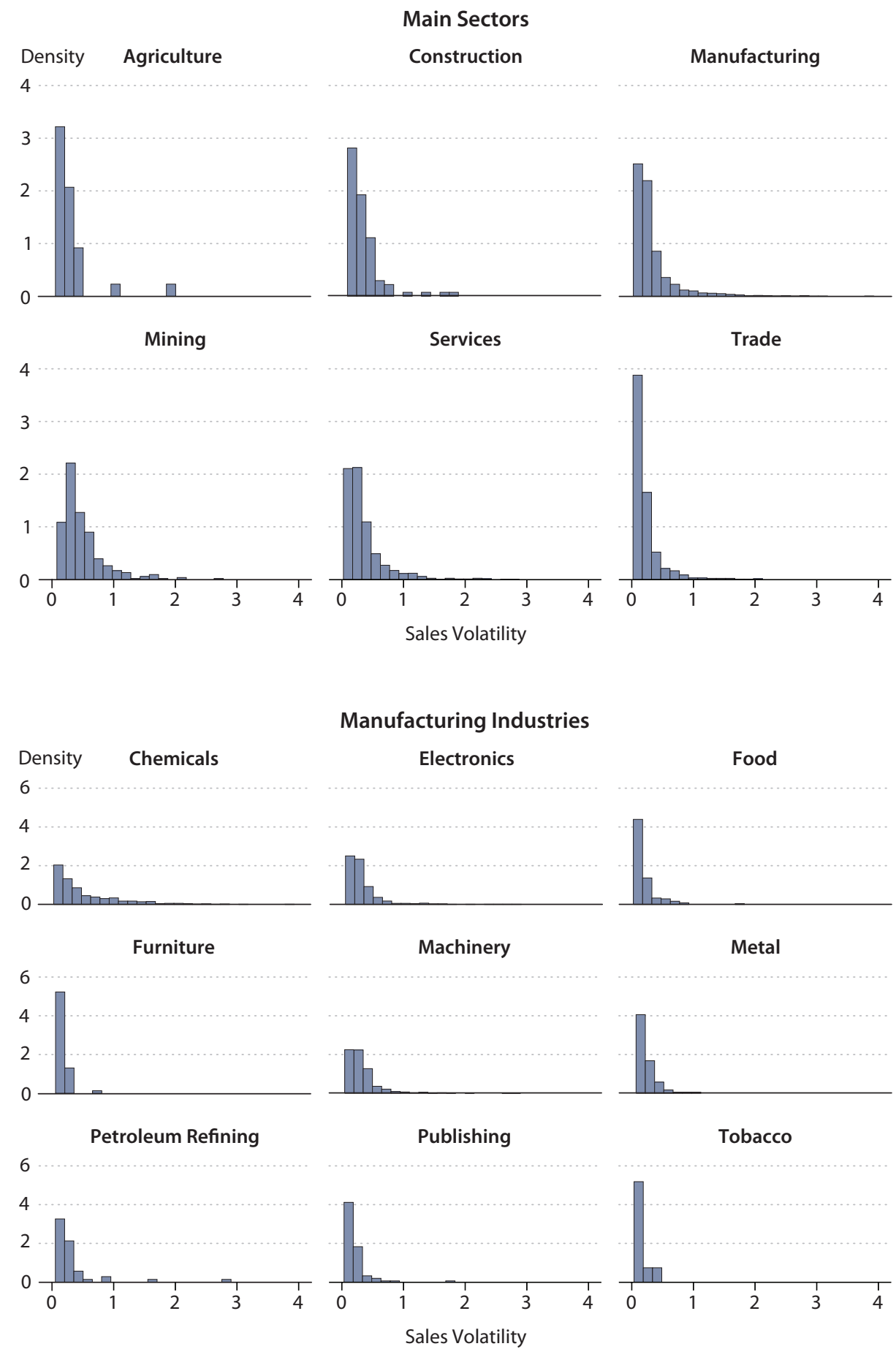

SOURCE: Compustat. 
Sánchez and Yurdagül

\section{Figure 23}

\section{Sales Volatility and Cash Ratio}

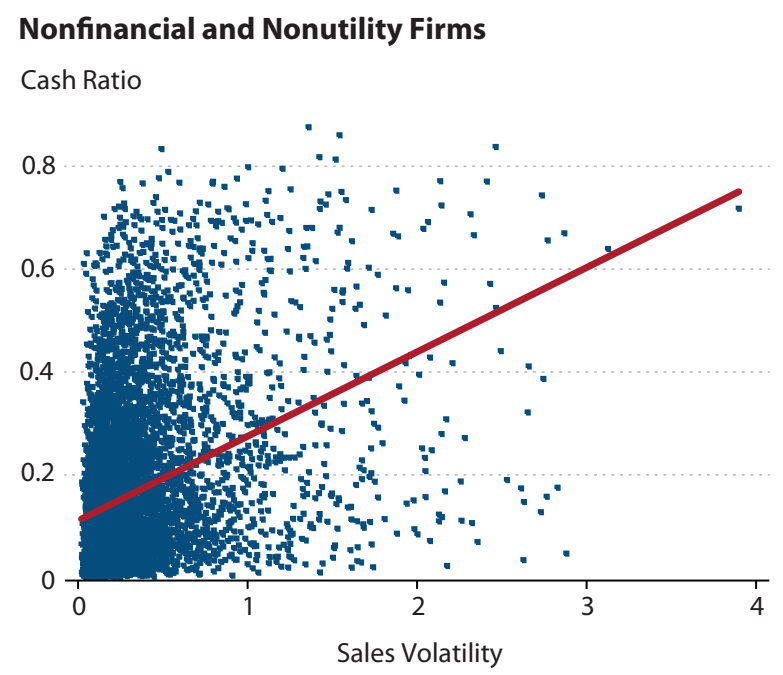

\section{Sectors}

Cash Ratio

0.4

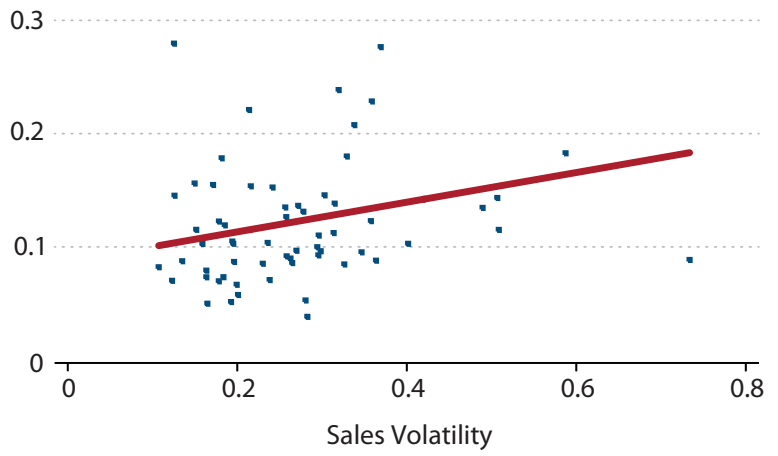

Figure 24

\section{Sales Volatility (Nonfinancial and Nonutility Firms)}
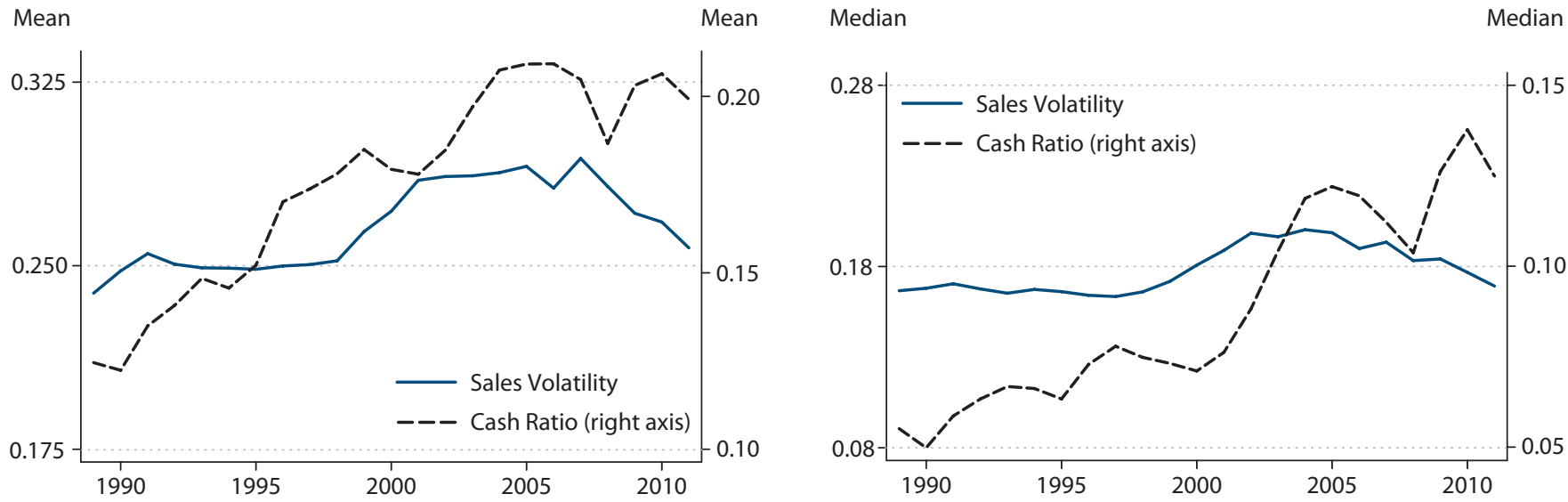

SOURCE: Compustat. 


\section{Figure 25}

\section{Distribution of Cash Flow Volatility (Nonfinancial and Nonutility Firms)}

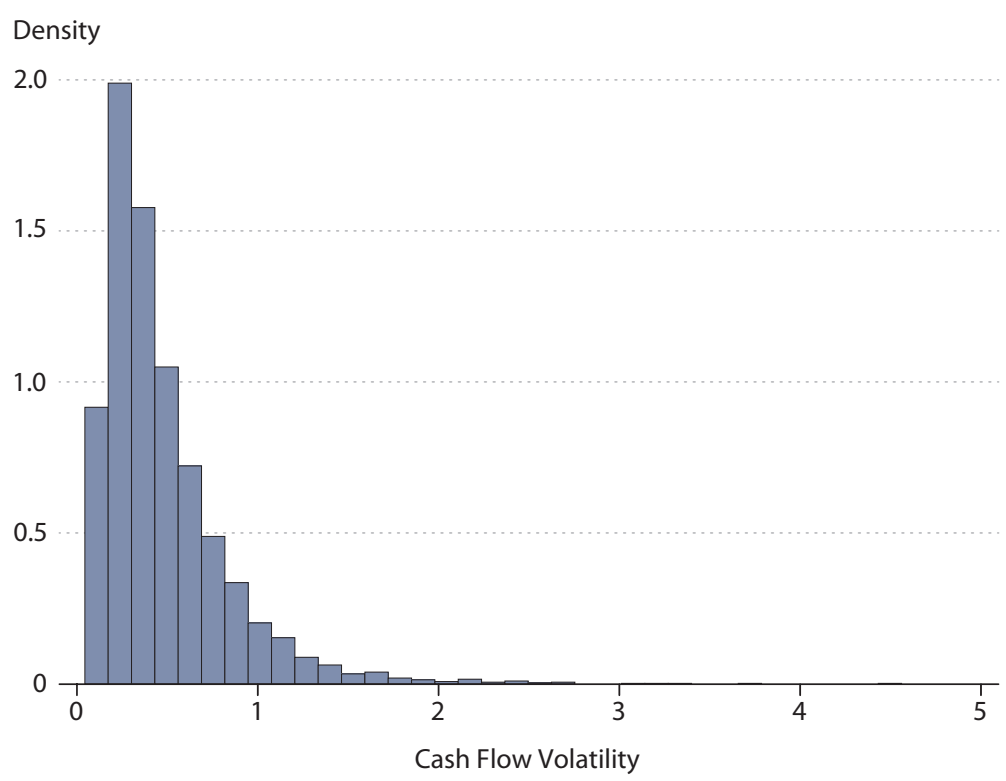

SOURCE: Compustat.

activities is simply to look at cash flow volatility. Here we define "cash flow" as earnings before interest after deducting income taxes paid and cash flow of dividends. Similar to the analysis presented above, firm-specific volatility of this variable is the SD over time for each firm:

$$
\text { CashFlow } \text { Volatility }_{i t}=\frac{1}{8} \sum_{j=t-8}^{t}\left(b_{i j}-\bar{b}_{i}^{(t)}\right)^{2} \text {, }
$$

where

$$
\begin{aligned}
& \bar{b}_{i}^{(t)}=\frac{1}{9} \sum_{j=t-8}^{t} b_{i j}, \text { and } \\
& b_{i t}=\log (\text { CashFlow })_{i t}-\log (\text { CashFlow })_{i t-1} .
\end{aligned}
$$

Since the measures of volatility capture similar factors, the patterns of distribution for this measure look similar to earlier ones with minor differences. The overall distribution shows very little volatility in the cash flows of many firms (Figure 25). Sector-wise analysis indicates that construction and mining have more firms with high volatility and higher means ( 0.61 and 0.59 , respectively). The highest dispersion among sectors is for mining, with an SD of 0.48 , which is much higher than the SD of 0.36 for the entire sample (Figure 26). Within manufacturing, the electronics industry has the flattest distribution and the highest mean, 0.57. 
Sánchez and Yurdagül

Figure 26

Distribution of Cash Flow Volatility Rate by Sectors
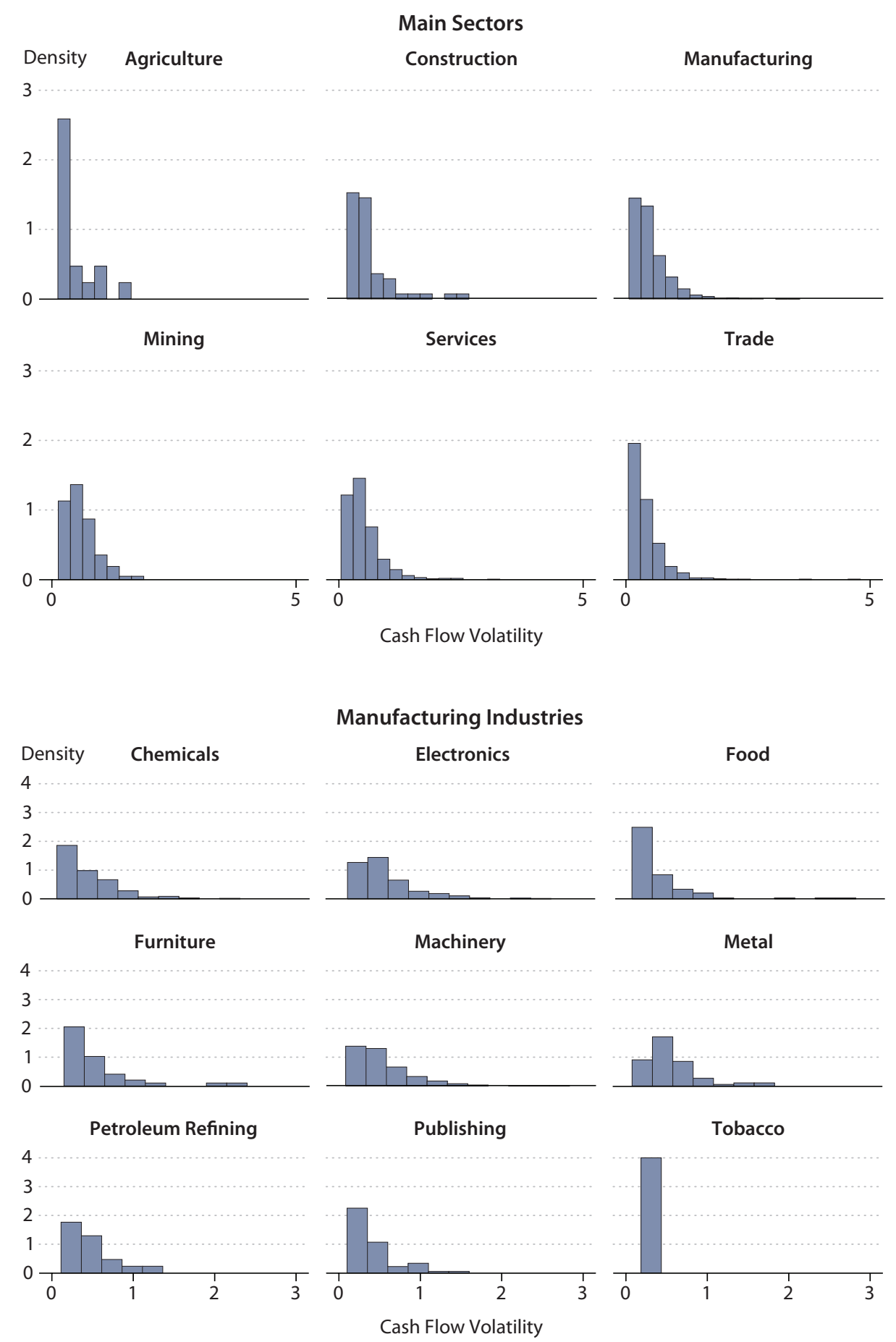

SOURCE: Compustat. 


\section{Figure 27}

\section{Cash Flow Volatility and Cash Ratio}

\section{Nonfinancial and Nonutility Firms}

Cash Ratio

0.8

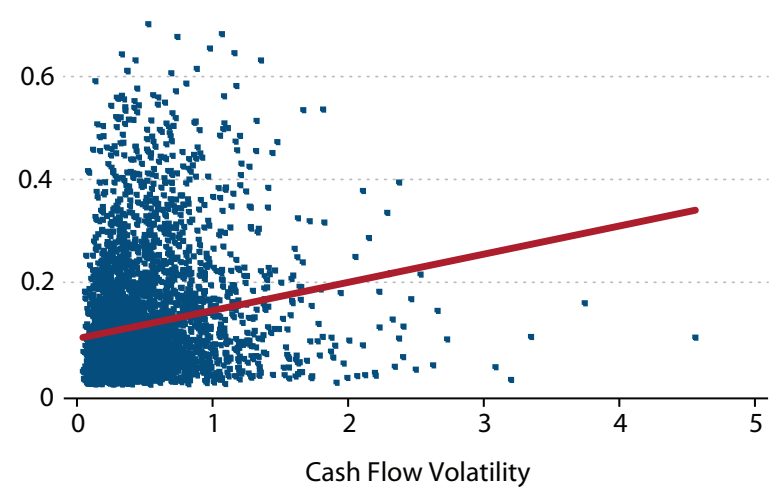

\section{Sectors}

Cash Ratio

0.4

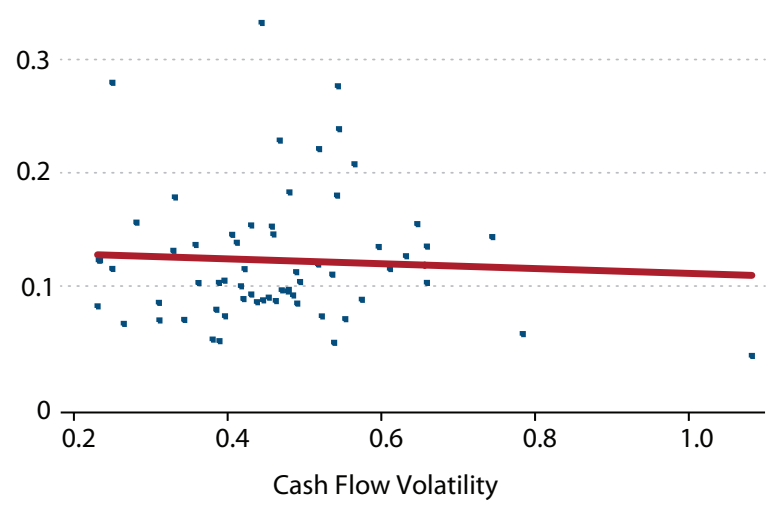

SOURCE: Compustat.

The left panel of Figure 27 shows a positive correlation of cash ratio with cash flow volatility across firms that resembles earlier measures of volatility. The right panel shows that the correlation across two-digit sectors is not positive, as it was for volatilities in productivity or sales. Two broad industries account for this difference: (i) fishing, hunting, and trapping and (ii) local and suburban transit and interurban highway passenger transportation, which have cash ratios around 0.04 and cash flow volatility around 1 .

Next we focus on the behavior of this measure of volatility across time. The overall pattern is nothing but steady (Figure 28). With the exception of an interval from 1998 to 2003 characterized by an annual growth rate of 2 percent in terms of the mean, there is dominant stagnation if volatility is captured by firms' cash flows.

Previously we discussed two different measures of idiosyncratic volatility that are constructed using different underlying sources-namely, productivity and sales. Within these two measures, productivity volatility was an example of a measure without a clearly increasing pattern to accompany the trend in the cash ratio, while sales volatility provided both cross-sectional and intertemporal evidence that higher volatility in firms' operations can partially account for higher cash holdings except in recent years. The measure constructed here using firms' cash flows is closer to the former, in the sense that it shows a positive correlation in the cross section but lacks a persistent increasing pattern throughout the study interval. Thus, the analysis here casts doubts about the role of firm-level volatility in accounting for the recent increase in cash holdings. 


\section{Figure 28}

\section{Cash Flow Volatility (Nonfinancial and Nonutility Firms)}
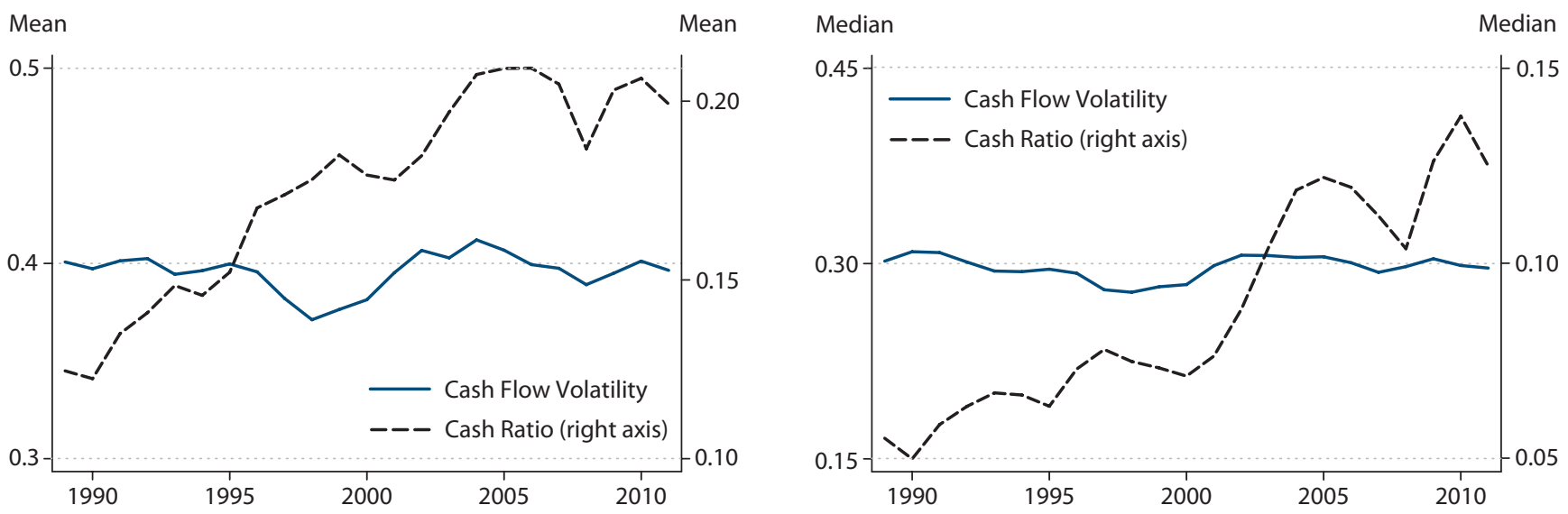

SOURCE: Compustat.

\section{THE ROLE OF AGGREGATE UNCERTAINTY}

In the previous section, we focused on idiosyncratic factors that could potentially account for cash hoarding. In a nutshell, we found little evidence to support the concept that such motivations are sufficient to account for the recent rise in cash holdings. In this section, we question the relevance of aggregate uncertainty in explaining the recent cash-hoarding phenomenon. Specifically, we focus on aggregate productivity uncertainty and policy uncertainty to study the potential for these factors to account for the recent rise in the cash ratio.

\section{Aggregate Productivity Volatility}

One indication of precautionary motives for hoarding cash can be the effects of aggregate volatility in productivity on firms' cash-holding behavior. In an earlier paper, Palazzo (2012) studies the relationship between firms' cash holdings and aggregate risk. He shows that firms with a positive correlation between cash flows and the aggregate shock build cash stocks as a cushion, in line with the previously explained precautionary motives. In this section, we conduct an alternative exercise by comparing the trend in aggregate productivity uncertainty and cash holdings.

Specifically, we construct a measure of volatility in aggregate productivity and show the evolution of this variable over time. In constructing this measure, we use the information on sales and number of employees of each firm in the Compustat sample. For each year we (i) aggregate sales and employment in the sample and (ii) use sales per worker as a measure of productivity. Then, similar to the volatility measure used previously, we compute the log-deviation from the previous year and calculate the measure of volatility as the SD in the past 9 years: 


\section{Figure 29}

\section{Aggregate Productivity Volatility (Nonfinancial and Nonutility Firms)}

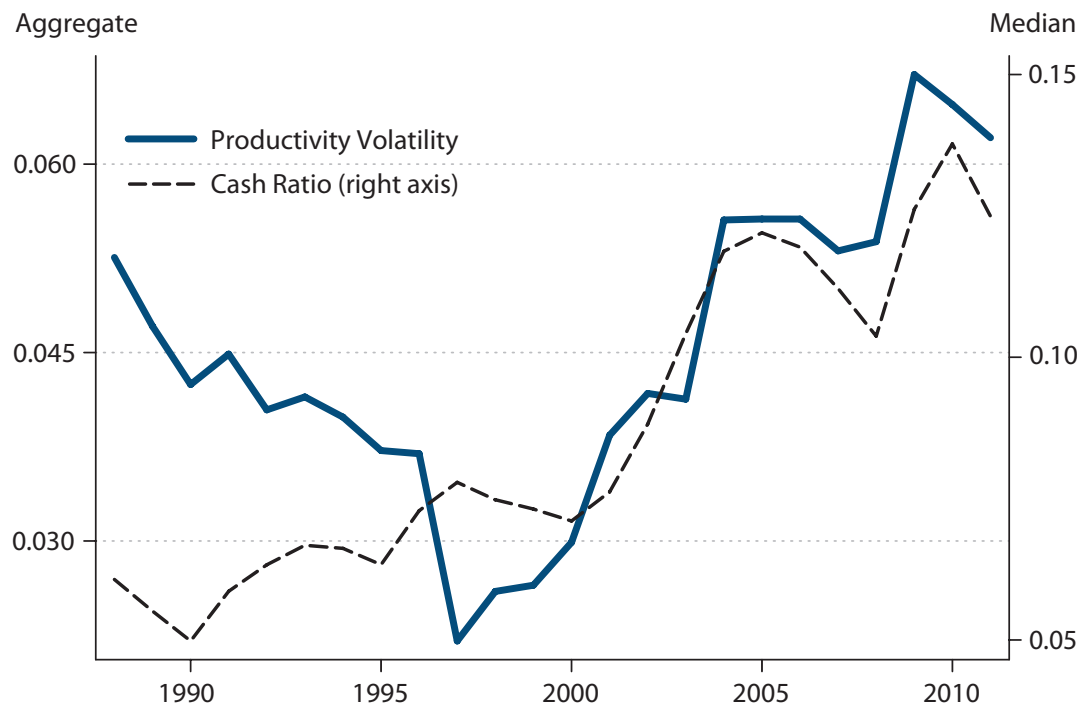

SOURCE: Compustat

$$
\text { AggregateProductivity Volatility }{ }_{i t}=\frac{1}{8} \sum_{j=t-8}^{t}\left(G_{i j}-\bar{G}_{i}^{(t)}\right)^{2}
$$

where

$$
\begin{aligned}
& \bar{G}^{(t)}=\frac{1}{9} \sum_{j=t-8}^{t} G_{j} \\
& G_{t}=\log (\text { AggregateProductivity })_{i t}-\log (\text { AggregateProductivity })_{i t-1}, \\
& \text { AggregateProductivity }_{i t}=\frac{\sum_{i=1}^{N} \text { Sales }_{i t}}{\sum_{i=1}^{N} \text { Employees }_{i t}},
\end{aligned}
$$

and $N$ is the number of firms in the sample.

Notice that here again, as for firm-level volatility, we use past volatility as the measure that firms take into account in their decisions regarding cash holdings. The idea is that firms learn from experience and that firm managers in the early 2000s did not know that the Great Recession was coming. $\cdot \underline{8}$ 
Figure 30

\section{Aggregate Policy Uncertainty (Nonfinancial and Nonutility Firms)}

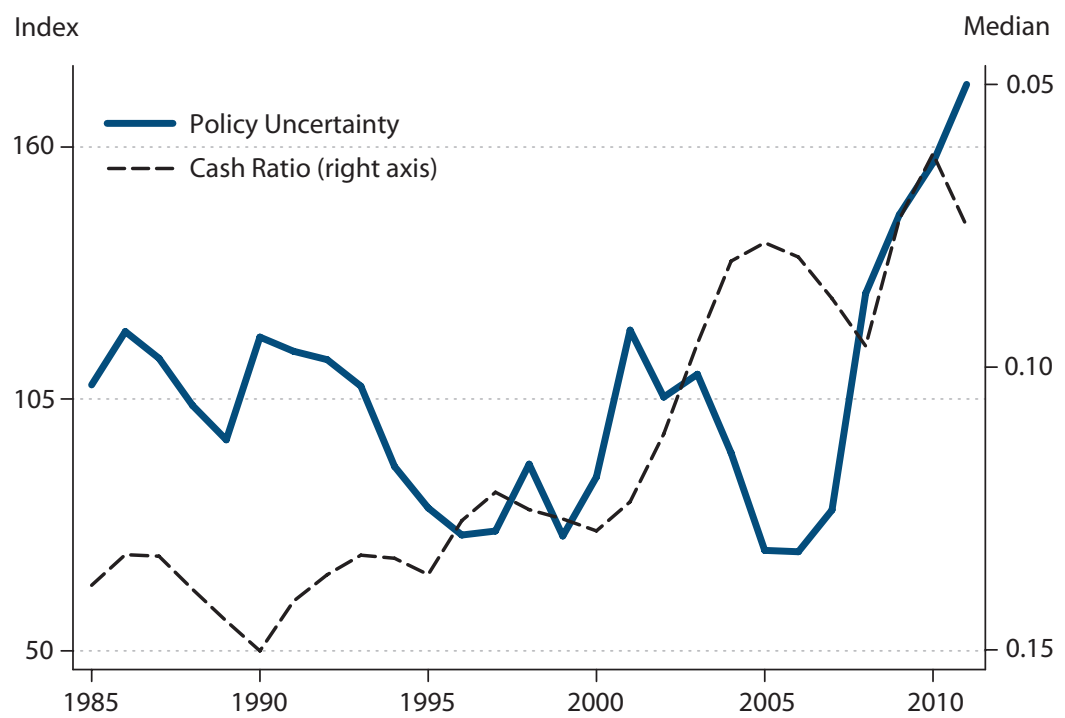

SOURCE: Baker, Bloom, and Davis (2013).

Figure 29 shows how the evolution of aggregate productivity volatility overlaps with that of the median cash ratio: The movements of the two variables coincide over the past decade. The aggregate productivity volatility in 2011 is 62 percent more than in 2001, while this rate is 64 percent for the median cash ratio. Consequently, the annual growth rates across these 10 years (beginning with 2001) are around 5 percent for both. These two statistics do not correlate well for the previous periods, however.

Two facts point to aggregate productivity volatility as a candidate in accounting for the recent trend in cash holdings: (i) the good correlation between firm-level uncertainty and firmlevel cash holdings and (ii) the increasing trends in volatility in aggregate productivity. While these facts are certainly not a proof, they do hint that firms' cash-holding behavior may be affected by uncertainty associated with aggregate productivity..

\section{Aggregate Policy Uncertainty}

Next, we use an excellent source to determine how (i) uncertainty associated with policy moves across time and (ii) it relates to the trend in cash holdings. In particular, we use the Economic Policy Uncertainty Index constructed by Baker, Bloom, and Davis (2012). They combine several measures to form this index: the frequency of articles in large newspapers discussing policy-related economic uncertainty, forthcoming expirations of tax code provisions, and disagreement among professional forecasters in predicting some economic statistics.

Figure 30 plots the evolution of the index against time, together with the median cash ratio. Although it is difficult to argue for overall comovement, there are several episodes where the 
two variables move in the same direction, in particular between 2008 and 2010 . One certain conclusion is that if we compare the correlation with the cash ratio of two measures of aggregate uncertainty we use here with that of the idiosyncratic factors presented previously, aggregate factors seem to dominate.

\section{CONCLUSION}

We analyzed data on publicly traded U.S. firms to shed light on the increasing trend in their cash holdings. By 2011, U.S. firms were holding four times as much cash as they were holding in 1995. Perhaps even more striking, the cash-to-asset ratio more than doubled between 2000 and 2010.

We first evaluated the role of idiosyncratic factors. The results suggest that some of these factors-namely, R\&D expenditures and cash-flow uncertainty-are likely to explain differences in the cross section and the early part of the aggregate trend. However, these factors stop short of keeping up with the rise in the cash-to-asset ratio that occurred after the mid-2000s. We then focused on the recent trends in aggregate uncertainty, particularly regarding aggregate productivity and policy. We find evidence suggesting the recent increase in cash holdings may be related to these aggregate factors.

\section{DATA APPENDIX}

We use Compustat as the data source for our calculations. Only U.S. firms are considered. Unless otherwise noted, we exclude financial firms (SIC classification between 6000 and 6999) and utility firms (SIC classification between 4900 and 4999), as is standard in the literature. Firmyear observations with negative total assets, sales, or capital are dropped. We trim from two tails at the 1 percent level the ratios of the following: cash to total assets, foreign income to total assets, $\mathrm{R} \& \mathrm{D}$ expenditure to total assets, and organizational intensity to total assets.

For cash holdings we use the variable "cash and short-term investments, che," and for assets we use "total assets, at." For R\&D expenditures we use "research and development expense, xrd," and for foreign income we use variable "pretax foreign income, pifo." The variable "property, plant and equipment (total (net)), ppent" is used for capital, and "operating income before depreciation, oibdp" is used for operating income. The variable "sales (net), sale" corresponds to the sales of a firm. Organizational capital expenditure is measured by "selling, general and administrative expense, xsga." We use "employees, emp" for a firm's employment. In order to calculate cash flows, we use "earnings before interest, ebitda," "total income taxes, txt," and "cash flow of dividends, dv." 


\section{Sánchez and Yurdagül}

\section{NOTES}

1 The appendix describes the data we use and provides the sampling restrictions.

$\underline{2}$ The implicit assumption for this logic to follow is that there is a stable relationship between these variables.

$\underline{3}$ All figures of intertemporal patterns with two $y$-axes preserve the same range relative to the average value of each particular series to facilitate the comparison.

4 See Black and Lynch (2005) for a survey of the definitions of organizational capital.

$\underline{5}$ See Lev and Radhakrishnan (2005) for a similar but more complex measure.

$\underline{6}$ In addition to using the past nine observations, we performed similar calculations with the past 5 and 11 observations with no change in results.

7 Since we use the previous eight observations together with the current one as a reference of volatility and then take the difference, the first observation is 1988 instead of 1979 as in the previous variables.

$\underline{8}$ This is in line with a large literature in economics in the early 2000s referring to the previous decade as the "Great Moderation."

9 One can note that the evolution of the aggregate volatility is quite different from the behavior of firm-specific volatility. To be clear, neither the fall during the 1990s nor the rise in the 2000s in aggregate productivity volatility is matched by corresponding patterns in firm-level volatility. These findings are in line with those of Comin and Mulani (2004) and Comin and Philippon (2006), who document the discrepancies between the behavior of aggregate and idiosyncratic volatility during the 1990 s.

\section{REFERENCES}

Baker, Scott R.; Bloom, Nicholas and Davis, Steven J. "Policy Uncertainty: A New Indicator." CentrePiece-The Magazine for Economic Performance, No. CEPCP362, Winter 2011/12, 16(3), pp. 21-23;

http://cep.Ise.ac.uk/pubs/download/cp362.pdf.

Bates, Thomas W.; Kahle, Kathleen M. and Stulz, René M. "Why Do U.S. Firms Hold So Much More Cash Than They Used To?" Journal of Finance, October 2009, 64(5), pp. 1985-2021.

Black, Sandra E. and Lynch, Lisa M. "Measuring Organizational Capital in the New Economy," in Carol Corrado, John Haltiwanger, and Daniel Sichel, eds., Measuring Capital in the New Economy (National Bureau of Economic Research Studies in Income and Wealth). Volume 65, Chap. 6. Chicago: University of Chicago Press, 2005, pp. 205-36.

Brunell, Don C. "Washington View: Uncertainty Keeping Businesses' Cash on the Sidelines." Columbian (Vancouver, WA), August 16, 2011; http://www.columbian.com/news/2011/aug/16/uncertainty-keeping-businesses-cash-on-the-sidelin/.

Comin, Diego and Mulani, Sunil. “Diverging Trends in Macro and Micro Volatility: Facts.” NBER Working Paper No. 10922, National Bureau of Economic Research, November 2004; http://www.nber.org/papers/w10922.pdf.

Comin, Diego and Philippon, Thomas. "The Rise in Firm-Level Volatility: Causes and Consequences," in Mark Gertler and Kenneth Rogoff, eds. NBER Macroeconomics Annual 2005. Volume 20. Cambridge, MA: MIT Press, 2006, pp. 167-228; http://www.nber.org/chapters/c0072.pdf.

Foley, Fritz C.; Hartzell, Jay C.; Titman, Sheridan and Twite, Garry. “Why Do Firms Hold So Much Cash? A Tax-Based Explanation." Journal of Financial Economics, December 2007, 86(3), pp. 579-607.

Lev, Baruch and Radhakrishnan, Suresh. "The Valuation of Organization Capital," in Carol Corrado, John Haltiwanger, and Daniel Sichel, eds., Measuring Capital in the New Economy (National Bureau of Economic Research Studies in Income and Wealth). Volume 65, Chap. 3. Chicago: University of Chicago Press, 2005, pp. 73-110.

Opler, Tim; Pinkowitz, Lee; Stulz, René and Williamson, Rohan. "The Determinants and Implications of Corporate Cash Holdings." Journal of Financial Economics, April 1999, 52(1), pp. 3-46. 
Palazzo, Berardino. "Cash Holdings, Risk, and Expected Returns." Journal of Financial Economics, April 2012, 104(1), pp. 162-85.

Pinkowitz, Lee; Stulz, René M. and Williamson, Rohan. "Multinationals and the High Cash Holdings Puzzle." NBER Working Paper No. 18120, National Bureau of Economic Research, June 2012; http://www.nber.org/papers/w18120.pdf?new window=1.

Speckbacher, Gerhard and Wentges, Paul. “A Note on Stakeholder Theory and Risk: Implications for Corporate Cash Holdings and Dividend Policy." Frontiers in Finance and Economics, April 2009, 6(1), pp. 51-72. 
